\title{
Grass strategies and grassland community responses to environmental drivers: a review
}

\author{
Laíse da Silveira Pontes $^{1}$ • Vincent Maire ${ }^{2} \cdot J_{\text {ürgen Schellberg }}{ }^{3} \cdot$ Frédérique Louault $^{4}$
}

Accepted: 4 May 2015 / Published online: 2 June 2015

(C) INRA and Springer-Verlag France 2015

\begin{abstract}
Grassland covers about one quarter of the Earth's land area and is currently estimated to contribute to the livelihoods of over 800 million people. Grassland provides ecosystem goods and services, mainly through the provisioning of milk and meat. Therefore, the proper use of grasslands will be essential for feeding the nine billion people that will inhabit planet Earth by 2050. In the context of a changing climate, we should better understand the interactions of environment, management and grass crop at individual, community and ecosystem levels. Functional ecology focuses on the roles and functions that species play in the community or ecosystem in which they occur. Functional ecology thus aims to understand how plant species adapt to environmental conditions and how management can alter this adaptation. Here, we review the latest advances in plant functional traits research and on species strategies to the main environmental factors occurring in grassland ecosystems: nutrient availability, grazing, cutting and shad-
\end{abstract}

Laíse da Silveira Pontes

laisepontes@iapar.br

1 IAPAR, Agronomic Institute of Paraná, CP 129, 84001-970 Ponta Grossa, PR, Brazil

2 Groupement de Recherche en Biologie Végétale \& Centre de Recherche sur les Interactions Bassins Versants-Ecosystèmes Aquatiques, Université du Québec à Trois-Rivières, 3351 Boulevard des Forges, CP 500, Trois-Rivières, Québec G9A 5H7, Canada

3 Institute of Crop Science and Resource Conservation, Crop Science Group, University of Bonn, Katzenburgweg 5,

53115 Bonn, Germany

4 INRA, UR0874 Ecosystème Prairial (UREP), 5 Chemin de Beaulieu, 63039 Clermont-Ferrand, France ing. Functional ecology also provides a framework to better understand how species strategies interact with the species composition at the community level. Therefore, the literature on community assembling theories in relation to ecosystem processes most relevant to grassland management and services is also reviewed. Finally, future research questions and some new orientations for grassland experts are offered in order to meet the challenge of maintaining productivity and preservation of these semi-natural environments in the face of global change.

Keywords Grasslands · Habitat-filtering · Functional ecology $\cdot$ Niche differentiation $\cdot$ Plant functional traits . Species abundance

\section{Contents}

1. Introduction

2. From plant functional traits to species strategies

2.1. Grass strategies along nutrient gradients

2.2. Grass strategies to tolerate or compensate for cutting/large herbivores grazing

2.3. Grass strategies to shading

2.4. Grass strategies faced to multiple stresses

2.5. Intraspecific trait variability

3. Scaling up from species strategies to species abundance

3.1. Community assembling rules: a brief review of niche-based processes

3.2. Which traits for which assembly process?

3.3. Which assembly process for which conditions?

3.4. Which assembly process for which status in the community?

3.5. From empirical to predictive approach

4. Perspectives in plant functional strategies 
4.1. Enlarged drivers and traits to define plant strategies

4.2. Predicting the optimal shift of traits in response to ongoing environment/management change using individual-based modelling

4.3. Going through the debate opposing niche-based theories

4.4. Distribution of traits within a species and a given environment and the delineation of species regional pool

4.5. Achieving functional targets in grassland ecosystems by theory-driven ecological management

5. Conclusions

Acknowledgments

References

\section{Introduction}

The grassland biome covers about one quarter of the Earth's land area (Ojima et al. 1993). Grasslands (Fig. 1) are currently estimated to contribute to the livelihoods of over 800 million people (Reynolds et al. 2005) and provide a range of ecosystem goods and services (Millenium Assessment 2005). They include fodder provision, soil stability and fertility including $\mathrm{C}$ sequestration, as well as water and climate regulation (de Bello et al. 2010). For instance, according to Soussana et al. (2013), the soil C sequestration by the world's permanent pastures could potentially offset up to $4 \%$ of the global greenhouse gas emissions. Proper grazing management, restoration of degraded lands and substitution of mineral $\mathrm{N}$ fertilizers by biological $\mathrm{N}$ fixation (Smith et al. 2008) are only some

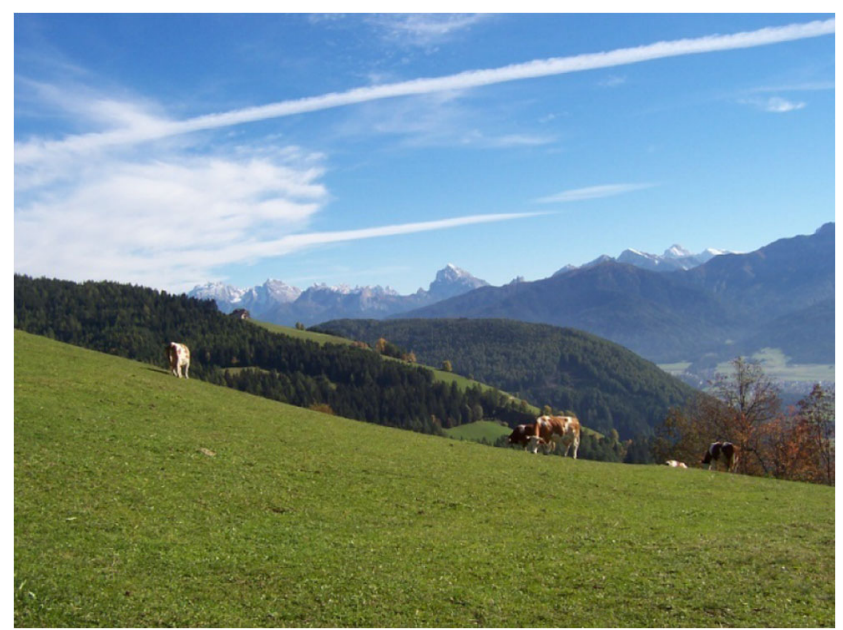

Fig. 1 Grassland contributes about $2 / 3$ to total agricultural land worldwide and provides a wide range of ecosystem services. Due the great variability of environmental conditions, yield potential and floristic composition, sustainable management of grassland requires a deep understanding of functional relationships between these factors examples of management tools that can achieve a significant role in order to provide the above-mentioned ecosystem services most adequately. The achievement of these goals will be essential for feeding the nine billion, especially in the face of the fact that the demand for animal-source products will increase faster than for other agricultural products (Herrero et al. 2013).

However, current grassland management does not necessarily consider functional relationships (qualitative and quantitative) between available resources and plant growth including competition and feedback regulation within plant communities, which is, however, required for optimizing production, using the natural resources efficiently and thereby providing ecosystem services such as promoting diversity and $\mathrm{C}$ sequestration in a most beneficial way. Usually, decision making on farms is mostly based on empirical observation of performance of the grass crop, but the underlying mechanisms determining grassland yield and quality are rarely considered. It is widely accepted that the approaches in functional ecology that have developed during the past three decades can significantly contribute to a better mechanistic understanding of processes and thus lead to reducing the uncertainty in management decisions.

In functional ecology, theories have been developed in order to understand how species adapt to environmental conditions (e.g. climate or management changes), and then to predict the variation in ecosystem functions underpinning ecosystem services. These theories are based on morphological, physiological and phenological properties of plants, i.e. on plant functional traits (Fig. 2), rather than on plant taxonomy (Violle et al. 2007).

Several easily measurable plant functional traits have been identified for individual plant species, summarized in a short list including standardized protocols for their assessment (Cornelissen et al. 2003). Further, these traits have been linked to functions that support ecosystem services, such as rate of decomposition and mineralization, nutrient retention and sedimentation, net primary productivity, evapotranspiration and feeding quality development for herbivory (de Bello et al. 2010). However, individual plant functional traits should not be considered in isolation because pairs or groups of traits often co-vary (Díaz et al. 2004). Quantifying these covariations and understanding why some sets of traits are closely coordinated leads us to the identification of single dimensions of functional strategy variation (Westoby et al. 2002; Wright et al. 2004; Garnier and Navas 2012). The strength of this approach is that it enables us to assess the effects of environmental factors on processes that govern community assembly and consequently also on ecosystem functioning.

The aim of this review is to give an overview on the widely accepted plant functional trait approach. We will first describe and evaluate this approach in order to better understand species' strategies to endure environmental filters, thereby focusing on nutrients, grazing or cutting and shade, since they are 


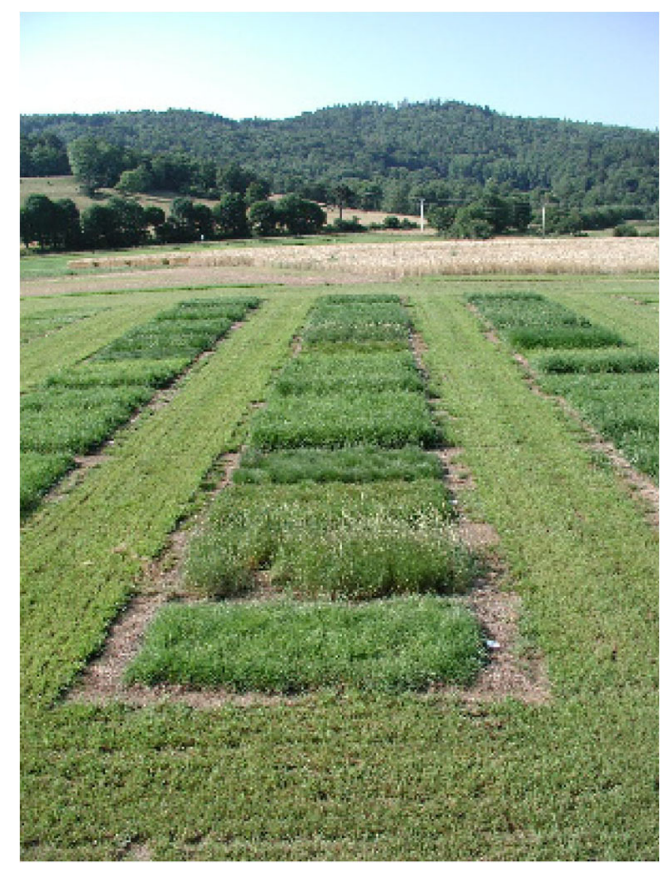

Fig. 2 Grass species exhibit very diverse expressions of functional traits, which are known to vary considerably when growing in mixed stands. In order to investigate the direct effect of plant functional traits on ecosystems processes (e.g. dry matter yield) under the same experimental field conditions and without interferences between species, they are first grown in pure stands and later arranged in welldefined mixtures. This photo shows field plots of perennial $C_{3}$ grass species from semi-natural mesic grasslands (e.g. Arrhenatherum elatius, D. glomerata, Elytrigia repens and Festuca arundinacea) at ClermontFerrand (France). It depicts from the photo that morphology of these species differ considerably

crucial in determining plant abundance and growth within grasslands and partly result from management practices. Then, in order to scale up from species strategies to species abundance in the community, we review three species assembling theories, including environmental filtering, competitive hierarchy and niche differentiation, and review trait-based models of community assembly in the context of managed grassland communities.

\section{From plant functional traits to species strategies}

Plant functional traits are useful tools to simply describe the fitness of the plant that is composed by three elements: growth, survival and reproduction that allow any species to persist, to accumulate resources and to transmit its genes to the next generation. Measured at the level of an individual organism, plant functional trait expression, i.e. its numerical value or categorical type, captures a plant function and modulates its fitness (Violle et al. 2007). For instance, a large plant height has been linked to high light interception rates (Violle et al. 2007), large root density is related to high nutrient absorption and high leaf nutrient content indicates low plant nutrient efficiency (Maire et al. 2009). Further, a large seed mass is an important predictor of establishment success, and seed output is an important predictor of dispersal (Westoby et al. 2002). At species level, a numerical plant functional trait is defined by its average and variability. The former reflects the central tendency of the species while the latter reflects the range of attributes that plant plasticity allows. It thereby considers the capacity of an organism to alter its morphology and/or physiology in response to environmental conditions as well as the selection of particular genotypes with particular trait attributes at the population level.

Across species, some plant functional traits are related to each other and co-vary along axes of specialization (Díaz et al. 2004) while others are independent (Maire et al. 2009, 2013a). Understanding whether these co-variations occur or not leads to the functional strategy concept. For instance, a well-known axis of specialization, i.e. the leaf economic spectrum (Wright et al. 2004; Reich 2014; see also axis 2 and 4 on Fig. 3), contrasts exploitative (large specific leaf area, leaf nitrogen content, photosynthetic rate and low leaf lifespan) vs. conservative plant (opposite syndrome) strategies, whereby the ability of a species to grow fast trades off with its resource use efficiency. An independent axis of specialization from the exploitative-conservative one concerns traits linked with plant size (e.g. leaf and sheath lengths, root and shoot biomass) (Grime 1993). Combinations of independent traits linked with each of the specialization axes define the set of strategies that a plant species can use to respond to different environmental drivers.

According to Grime (2001), species strategies are related to "groupings of similar or analogous genetic characteristics which recur widely among species or populations and cause them to exhibit similarities in ecology". Grime (1993) gives also the following definition for species strategies: "major recurring axes of adaptive specialization in life history and in the physiology of the adult (established) organism which appear to be associated with variation in the duration and quality of the opportunities which habitats provide for resource capture, growth and reproduction". He has developed the well-known ecological strategy scheme, the CSR triangle (Grime 1977; Grime et al. 1988), which has been vigorously debated in the scientific community. The R (ruderal) dimension represents species able to disperse rapidly with a short life cycle. The $\mathrm{C}$ (competitor) dimension represents species with a tall stature, while the $\mathrm{S}$ (stress tolerator) dimension represents species that are well adapted to environmental conditions inducing plant stress because of their long lifespan and large root system.

A variety of other ecological strategy schemes have been proposed. For instance, the Leaf, Height, Seed (LHS) of Westoby (1998) represent a more reductive approach (but also quantitative) of strategies than the CSR model. It is based on 


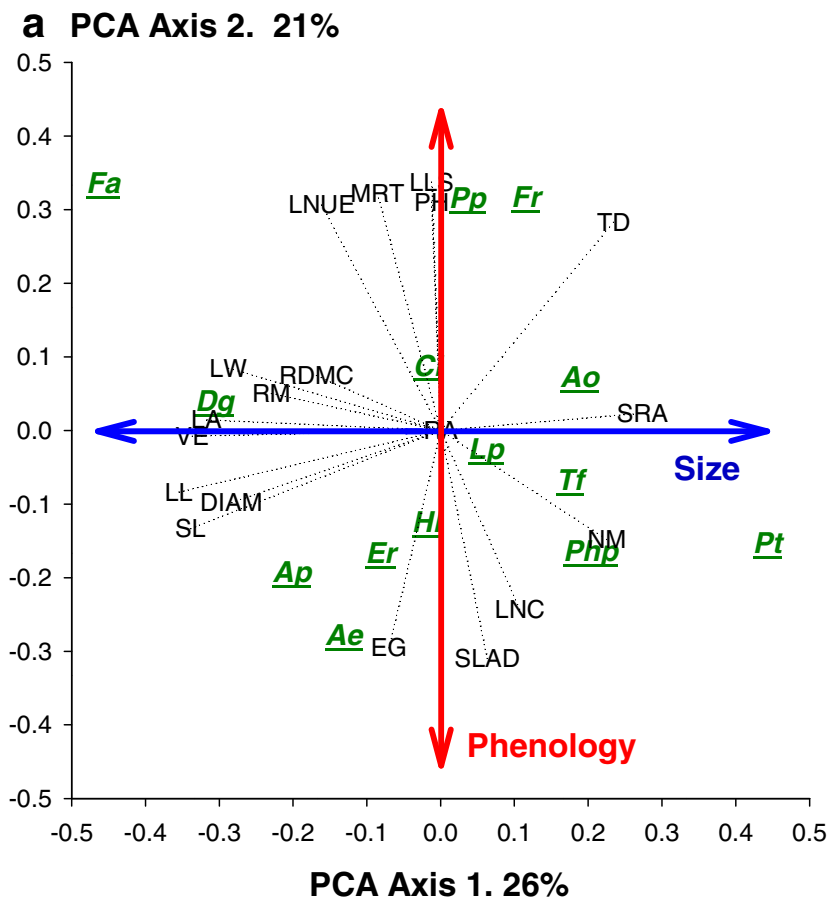

Fig. 3 Co-variation of plant functional traits along the four first leading dimensions (a axes 1 and 2; b axes 3 and 4) of a principal component analysis extracted from a trait $\times$ species matrix, including 12 grass species and 28 plant traits. Axis 1 (blue): trade-off between root-scale and size; axis 2 (red): vegetative phenology axis; axis 3 (orange): trade-off between the investments in root $\mathrm{NO}_{3}{ }^{-}$and $\mathrm{NH}_{4}{ }^{+}$transporters; axis 4 (pink): $\mathrm{N}$ acquisition/conservation trade-off. Abbreviations of traits are as follows: $E G$, earliness of growth; DIAM, root diameter; ImaxNH4, root maximal uptake capacity for $\mathrm{NH}_{4}{ }^{+}$; ImaxNO3, root maximal uptake capacity for $\mathrm{NO}_{3}{ }^{-}$; ITOTM, root maximal uptake capacity for $\mathrm{NO}_{3}{ }^{-}$and $\mathrm{NH}_{4}{ }^{+} ; L A$, individual leaf lamina area; $L D M C$, leaf dry matter content; $L L$, leaf length; $L L S$, leaf lifespan; $L N C$, leaf lamina nitrogen $(\mathrm{N})$ content; $L N U E$, leaf $\mathrm{N}$ use efficiency; $L W$, individual leaf lamina water; MRTN,

three axes: leaf mass per area, height and seed mass, which are all linked to the establishment, persistence and dispersion capacity, respectively. Therefore, based on the concepts cited above, the strategies are expected to have the purpose for optimal spread of genes which carry the species traits (Westoby et al. 2002).

Plant functional traits and functional strategies determine how species respond to their environment. Apart from expressing response to disturbance or taking advantage of favourable growth, plant functional traits determine also how species affect local resources (Devictor et al. 2010). Indeed, plant functional traits have been classified as response traits, i.e. traits that express the response of plants to environmental factors such as resources and disturbances, and effect traits, i.e. traits that determine effects of plants on ecosystem functions (Lavorel and Garnier 2002). Therefore, it has been proposed that species' positions within a multidimensional trait space may represent their functional niche (Violle and Jiang 2009; Devictor et al. 2010), i.e. the subset of the $n$-dimensional space of:

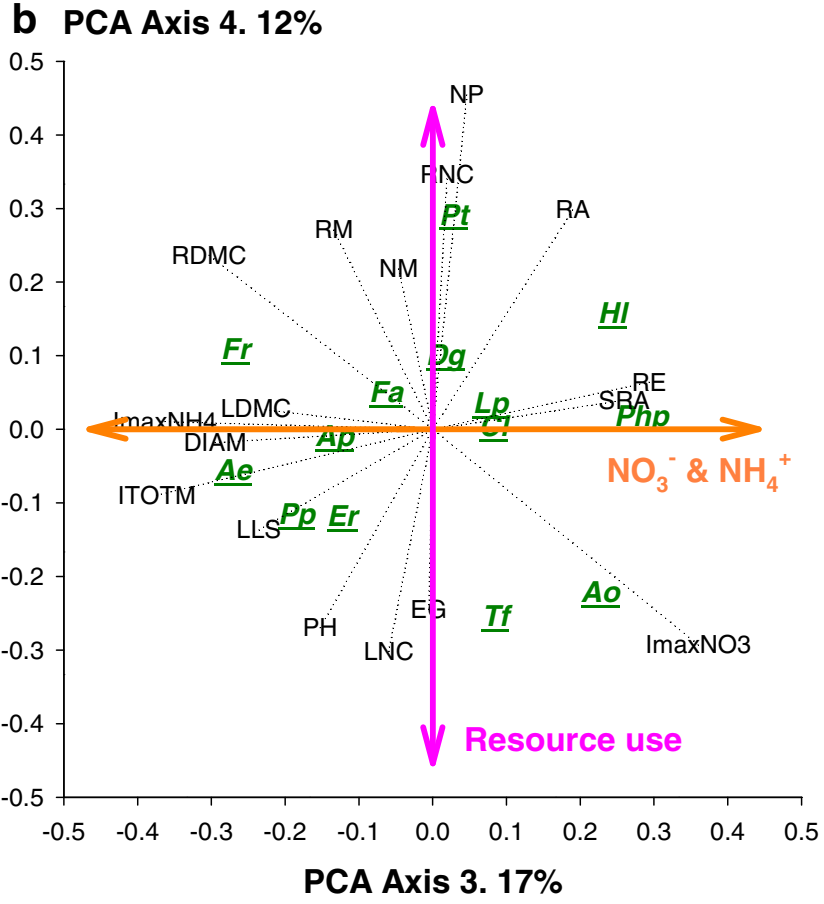

mean $\mathrm{N}$ residence time; $N G$, number of growing leaves; $N M$, number of mature leaves; $N P$, shoot $\mathrm{N}$ productivity; $P H$, phyllochron; $R A$, root area per soil volume; $R D M C$, root dry matter content; $R E$, leaf $\mathrm{N}$ resorption rate; $R M$, root mass per soil volume; $R N C$, root N content; $S L / L L$, ratio between the sheath and the leaf lengths; $S L$, sheath length; $S L A$, specific leaf area; $S R A$, specific root area: root area per root $\mathrm{DM} ; T D$, tiller density; $V E$, vegetative height. Species codes: Alopecurus pratensis (Ap), Anthoxanthum odoratum (Ao), Arrhenatherum elatius (Ae), D. glomerata (Dg), E. repens (Er), F. arundinacea (Fa), Festuca rubra (Fr), Holcus lanatus (Hl), Lolium perenne (Lp), L. perenne cv. Clerpin (Cl), Phleum pratense (Php), Poa pratensis $(\mathrm{Pp})$, Poa trivialis $(\mathrm{Pt})$, Trisetum flavescens (Tf). Adapted from Maire et al. (2012b)

1. All possible environmental conditions in which a species can survive with and without species interactions (Grinnell 1917; Hutchinson 1957), and also

2. All possible plant functions with which a species will modify its habitat and the chemistry and availability of environmental resources (Elton 1927).

These two definitions of the plant functional niche, which are originally derived from plant and animal ecology, echo the recent response-effect framework, proposed by Lavorel and Garnier (2002) and further refined by Suding et al. (2008). An individual plant functional trait can be seen either as responding to the environment or having an effect on it. For example, specific leaf area, which is identified usually as a response trait linking individual responses to plant interactions with the community structure in subalpine grasslands (Gross et al. 2009), is also associated with the forage quality (e.g. dry matter digestibility, Fig. 4) and can therefore also be identified as an effect trait. 
Fig. 4 Ordination of traits, above-ground net primary productivity (ANPP), pepsincellulase dry matter digestibility (PCDMD) and species $(n=39)$ by canonical correlations analysis. The first two axes represent $51 \%$ of the overall variation in the data set. See Fig. 3 for species and traits codes

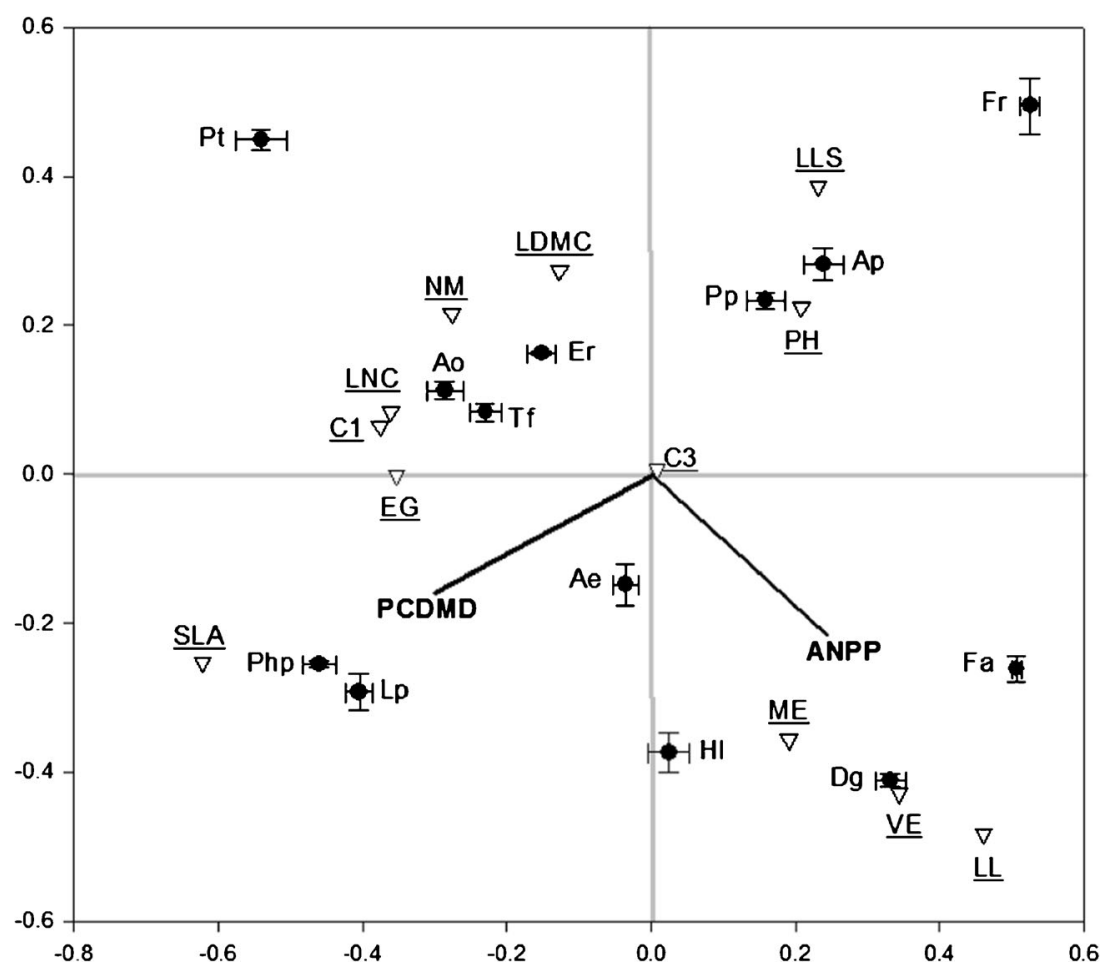

Below, we will focus particularly on traits implicated in the grasses' strategies to cope with different abiotic and biotic conditions. We do so because a central goal in grassland ecology is to identify traits of species that are responsible for the trade-offs that underpin ecological strategies in relation to environmental conditions (Westoby 1998), including those related to future climate change (temperature, rainfall) and management response to this change. We concentrated mainly on grasses for the reason that grasses are the dominant plants of grasslands (Gibson 2009; Woodward 2008), since they have developed coexistence strategies with herbivores. Further, focusing on Poaceae, the fifth most speciose plant family (Gibson 2009), a large interspecific variation of trait expression can be studied, as well as a large range of strategies (Craine et al. 1999; Ryser and Urbas 2000; Al Haj Khaled et al. 2005; Sugiyama 2005).

\subsection{Grass strategies along nutrient gradients}

It is one of the earliest observations in the history of grassland management that nutrients such as $\mathrm{N}, \mathrm{P}$ and $\mathrm{K}$ are most important for productivity and species assembly on grassland (Hejcman et al. 2013). From functional ecology research, we understand that soil nutrients represent a filter which affect the ecological niche dimension and modify the set of species (Harpole and Tilman 2007). Along these lines, and based on the approach presented by Violle and Jiang (2009), Schellberg and da Pontes (2012) have shown that community-weighted mean traits along a nutrient gradient (which in their case is $\mathrm{N}$ supply) can be used to estimate the optimal position of the species along the $\mathrm{N}$ fertilizer gradients. This allows identifying the ecological niche position by a mean trait value derived from standardized databases and from field measurements and the trait values range that is exhibited by a particular species. Thus, community-weighted mean traits along an environmental gradient provide a good assessment of trait-environment relationships (Schellberg and da Pontes 2012).

In relation to nutrient acquisition and use, the leaf economic spectrum is an axis of specialization that has been first defined at the global scale (Wright et al. 2004; Al Haj Khaled et al. 2005). It is based on traits like leaf nitrogen content, specific leaf area and leaf photosynthetic rate and contrasts exploitative vs. conservative plant types on their ability to colonize, grow and reproduce fast or slow, respectively. The precedent traits have been identified as response traits to N supply (Al Haj Khaled et al. 2005; Pontes et al. 2010).

At the local scale of low-mountain grasslands, Maire et al. (2009) further showed in a study with 13 perennial grasses that N-exploitative species are characterized by high leaf nitrogen content, high root uptake capacity and low leaf $\mathrm{N}$ use efficiency, while $\mathrm{N}$-conservative species exhibit the opposite trait syndrome. The positive correlation between root uptake capacity and leaf nitrogen content has been also evidenced in other studies (Poorter et al. 1991; Wright and Westoby 2000). Further, high leaf nitrogen content conferred low leaf $\mathrm{N}$ use efficiency, leading to low biomass production per unit $\mathrm{N}$ (Soussana et al. 2005). This consistent negative relationship 
observed between leaf $\mathrm{N}$ use efficiency and leaf nitrogen content explains the previous observation by Pontes et al. (2007), which suggests that $\mathrm{N}$ yield correlates negatively across species with leaf nitrogen content per unit fresh matter. This is because leaf nitrogen content per unit fresh matter is negatively correlated to above-ground productivity, regardless of $\mathrm{N}$ supply level. In other words, a high leaf nitrogen content per unit fresh matter would reduce above-ground productivity through a decline in $\mathrm{N}$ yield, as for the same leaf volume more dry-matter and more $\mathrm{N}$ per unit dry-matter is required.

Grasses are monocotyledones plants exhibiting unidirectional growth of their leaves. The leaf growth zone at the base of the leaf blade is the main site of growth where anatomical and chemical characteristics of leaves originate. The leaf elongation rate and the length of the leaf growth zone (region where cell division and expansion occurs) exhibit negative correlations to leaf dry matter content (Arredondo and Schnyder 2003). Leaf nitrogen content is closely associated with $\mathrm{N}$ deposited during cell production (Gastal and Nelson 1994). Therefore, Pontes et al. (2007) have suggested that N yield declines with $\mathrm{N}$ deposition per unit cell volume in the growth zone. Accordingly, the relative growth rate of grasses is also negatively correlated with leaf nitrogen content (Soussana et al. 2005) because of a reduction in $\mathrm{N}$ yield, which is the ratio of biomass production to the amount of $\mathrm{N}$ in the plant for a given unit of time. Therefore, a large $\mathrm{N}$ dilution would result in a fast regrowth rate through increased $\mathrm{N}$ yield.

In trait response studies along nutrient gradients, the majority of studies have focused on a unique gradient (including either natural or fertilization gradient), especially total soil nitrogen, considering that all soil variables co-vary along it (e.g. Bernard-Verdier et al. 2012). However, the type of nutrient is critical because it affects the strategies used by the species to acquire nutrients and the importance of biotic interactions (Schellberg and Pontes 2012). For instance, at local scale, grass species can exhibit strategic preferences in root uptake capacities between $\mathrm{NO}_{3}{ }^{-}$and $\mathrm{NH}_{4}{ }^{+}$to coexist within a given community, with dominant species preferring nitrate and stabilized rare species preferring ammonium (Maire et al. 2009). At the global scale, it has been recently shown that strategies of nitrogen and water acquisition are independent. They co-vary with independent soil dimensions (soil $\mathrm{pH}$ and soil available phosphorus) and they both lead to increased leaf photosynthetic rate (Maire et al. 2015, but see Reich 2014 defining water-nitrogen strategies at a local scale). How each resource is linked with a specific strategy of resource capture is a further step to investigate in order to better predict the interactive effects of multiple resource gradients.

\subsection{Grass strategies to tolerate or compensate for cutting/large herbivores grazing}

Adaptive responses of species to frequent defoliation may be similar to the responses to high nutrient availability (Lavorel et al. 2007). Indeed, several authors have suggested that a high growth rate can be considered as a mechanism of tolerance to defoliation (McIntyre et al. 1999; Westoby 1999; Díaz et al. 2001). For instance, Dactylis glomerata L., a perennial grass species, is known to compensate for the effects of disturbance by rapid growth rates (Gross et al. 2007a). Conversely, characteristics that promote adaptation to low productivity habitats are associated with low palatability (Niemann et al. 1992; Perez-Harguindeguy et al. 2003), which is a mechanism of resistance to defoliation, as defined by Briske (1996). Therefore, chemical composition traits (e.g. cell soluble content, shoot cellulose and lignin) are important indicators of avoidance mechanisms, since they affect species' palatability. The avoidance mechanisms can also be found through traits allowing plants to escape the defoliation in space (linked to abundance, size and shape of the prostrate plants) or in time (related to phenology and dormancy) (McIntyre et al. 1999). Interestingly enough, Pontes et al. (2010) showed that changes in above-ground productivity due to changes in cutting frequency can be explained by traits linked to both tolerance and avoidance mechanisms. The first can be explained, for instance, by the changes in the number of leaves, since a large number of leaves are linked to an increased opportunity for photosynthesis (Gutschick 1999; Franklin and Agren 2002), and the second by the changes in plant stature and palatability. Del-Val and Crawley (2005) has argued that these two mechanisms, i.e. tolerance and avoidance to defoliation, are not mutually exclusive.

Several advances in the search for associations between traits and habitat characteristics have contributed to predict the behaviour of species communities in response to defoliation. For instance, Díaz et al. (2001) indicated that the best prediction of species response to grazing was achieved by combining plant height, life history (because annuals are favoured by grazing and perennials are disadvantaged, Díaz et al. 2006) and leaf mass. Small height and leaf size were both associated with grazing avoidance. Height at maturity is also an important trait used as a predictor of the response to cutting because it expresses growth performance between two subsequent disturbance events. However, in a synthesis elaborated by Díaz et al. (2006), the authors argued that climatic (e.g. dry vs. humid climates) and historical (short or long grazing history; grazing regime, i.e. frequency, intensity) contexts are essential for understanding plant trait responses to grazing, since some response patterns were modified by particular combinations of precipitation and herbivory. Also, for many traits, response to grazing appears modulated by productivity (Pakeman 2004). 


\subsection{Grass strategies to shading}

Plants living in dense herbaceous communities, on forest understories or even in grassland gaps (Seidlova et al. 2009), experience a strong reduction in radiation intensity and particularly in photosynthetically active radiation (PAR, 400$700 \mathrm{~nm}$ ). At the same time, they experience light quality changes because of wave length-dependent light absorption and reflection by surrounding vegetation (Franklin 2008; Gommers et al. 2013). Changes in light quality include a decrease in the intensity of red to far-red light intensity, which is detected by the phytochrome family of plant photoreceptors (Franklin 2008). Despite most grasses are adapted to growing in full sun habitats, they may show a capacity to alter leaf, shoot and canopy level traits to cope with quantity-qualityrelated light heterogeneity. Therefore, their growth performance will depend on their ability to tolerate or overcome declining photon flux density. For instance, suites of traits improving species' capacity to cope with low light conditions are high chlorophyll content, low foliage aggregation and low leaf inclination angle (see Niinemets 2010 for a review). However, grass species differ in a large number of physiological and morphological traits according to their shade strategies.

Two different plant strategies exist to deal with shade, avoidance and tolerance (Franklin 2008; Gommers et al. 2013). The ability of individual plants to effectively tolerate or avoid shading by neighbouring vegetation significantly enhances their competitive ability, hence having a strong influence on community structure and dynamics (Franklin 2008; Valladares et al. 2012). Consequently, there is an expanding interest in these shade strategies, since, for example, important impacts of global change, such as climate change, on plant communities are mediated by the shade tolerance of coexisting plant species (Valladares and Niinemets 2008). For instance, elevated temperatures may alter plant growth and leaf area production and, consequently, the availability of light for the components in the communities.

In shade-avoiding species, the perception of low ratio of red to far-red wavelengths results in a suite of developmental responses, collectively referred to as the "shade avoidance syndrome" (Smith and Whitelam 1997). According to Gommers et al. (2013), shade-intolerant species exhibit this shade avoidance syndrome by a suite of morphological traits that allows them to position leaves in higher canopy strata, including accelerated elongation of hypocotyls, internodes and petioles as well as upward leaf movement (hyponasty) and accelerated flowering and apical dominance. These changes in morphological traits lead to carbon being allocated towards stem elongation, in order to overtop competing vegetation. However, this goes to the expense of root and leaf development (Gommers et al. 2013), and therefore affects yield and nutritive value of grass species (e.g. Peri et al.
2007; Devkota et al. 2009; Kyriazopoulos et al. 2012). On the other hand, in mixtures, differences in height between grass species promotes complementarity for light due an above-ground space partitioning, which may lead to an overyielding (e.g. Gross et al. 2007b). Flowering is usually accelerated when the plant is unable to overtop competing vegetation; hence, they promote seed set and enhance the profitability of reproductive success (see Franklin 2008 for a review about light-quality pathway mediating shade avoidance syndrome, such as acceleration of flowering at low red/ far-red ratio).

Shade avoidance syndrome is common in vegetation where all plant species are of approximately similar height, such as grasslands (Gommers et al. 2013). By contrast, some species need to adapt their phenotype in order to cope permanently with shaded environments, such as in integrated croplivestock systems with trees (see Fig. 5 for an example of these systems in South America), where it is impossible to outgrow the tall neighbouring trees. In these systems, a shade-tolerance response seems more desirable than a shade-avoidance strategy.

According to Valladares and Niinemets (2008), shade tolerance is an ecological concept that refers to the capacity of a given plant to tolerate low light levels. Research about the ecology and ecophysiology of shade-tolerant species, particularly of tree seedlings, has demonstrated that this strategy is not only a lack of the classic shade-avoidance syndrome, but also a complex and specific adaptation to life in shade (Gommers et al. 2013). Two partly contrasting hypotheses on the suites of traits responsible for species' shade tolerance have been proposed: maximization of net carbon gain in low light (Givnish 1988, for review) and maximization of the resistance to biotic and abiotic stresses in the understory, i.e. the stress tolerance hypothesis (Kitajima 1994; Valladares and Niinemets 2008). The "carbon gain hypothesis" defines shade tolerance as the maximization of light capture and use in photosynthesis together with the minimization of respiration costs for maintenance (Givnish 1988).

Species usually try to optimize light capture and utilization by increasing their specific leaf area, lowering chlorophyll $\mathrm{a} / \mathrm{b}$ ratios and increasing photosystems II/I ratios (Shipley and Almeida-Cortez 2003; Gommers et al. 2013). However, a high specific leaf area can have negative consequences for plants growing under reduced radiation intensities because producing a large leaf area at little construction cost makes these leaves sensitive to mechanical stress and facilitate defoliation by herbivory (Van Arendonk and Poorter 1994; Duru et al. 2004). Hence, some shade-tolerant species may not maximize growth at low light, but invest in tissues improving defense and assimilate storage, which permits plants to tolerate periods of low light close to or below the whole-plant light compensation point (Valladares and Niinemets 2008). 
Fig. 5 Photos of integrated croplivestock systems with trees and cattle grazing on a cool season grass pasture (right) and with warm season grasses $(l e f t)$. "IAPAR", Ponta Grossa/PR, Brazil
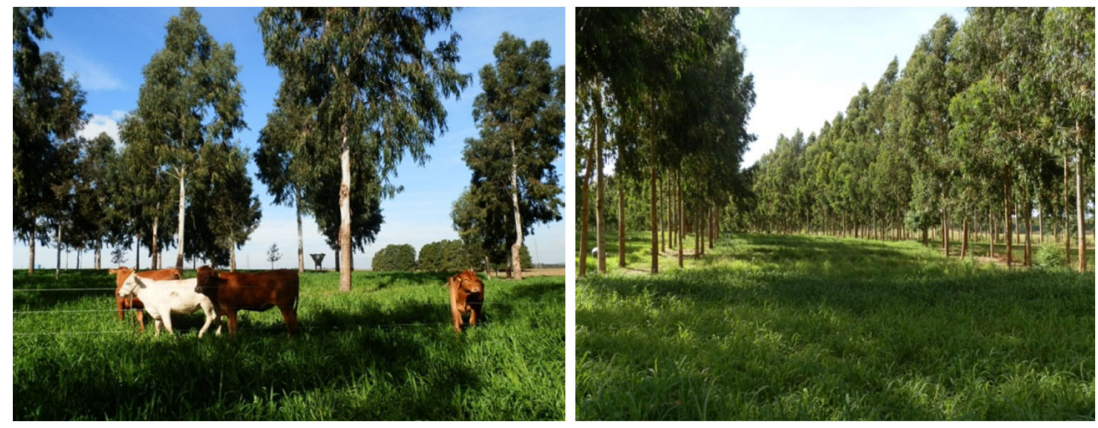

Various shade tolerators therefore appear to channel metabolic energy away from leaf elongation and optimal photosynthesis towards leaf survival. This difference implies that some shade-tolerant species exhibit a more conservative growth strategy with significantly more time available to fill storage tissue (Valladares and Niinemets 2008). Therefore, shadetolerant species may have different ways to tolerate shade, i.e. by maximization of carbon gain and stress tolerance (i.e. maximization of the resistance to biotic and abiotic stresses) strategy. It seems that these shading strategies have similar trait syndromes like the one implied in the nutrients acquisition vs. conservation strategies.

However, some traits can be affected in the same sense in both shade-avoiding and shade-tolerating strategies, and in both tolerance strategies, i.e., carbon gain vs. stress tolerance. For instance, an increased specific leaf area can be observed in both shade-avoiding and shade-tolerating plants (Gommers et al. 2013). Although there is a broad consensus on the traits improving light harvesting, much less is known about the relative importance of various traits in altering species shade tolerance (Niinemets 2010).

\subsection{Grass strategies faced to multiple stresses}

Plant functional traits usually co-vary along axes of specialization (Díaz et al. 2004; Maire et al. 2013a, Fig. 3), reflecting a different trade-off for plant functioning (Suding et al. 2003; Westoby and Wright 2006). However, tolerance to shade can also be inversely associated with tolerance to others limiting factors, such as drought (Valladares and Niinemets 2008) and nutrients availability. For instance, there are conflicting requirements for shade tolerance (e.g. high foliage area) and drought tolerance (e.g. high biomass investments into roots). In addition, according to Hirose and Bazzaz (1998), there is a trade-off between nitrogen-use efficiency and light-use efficiency such that light-use efficiency increased with increasing leaf $\mathrm{N}$ content, while nitrogen-use efficiency increased with increasing light availability within the canopy.

The co-occurrence of multiple stresses can dramatically alter the capacity of a given species to tolerate low light (Valladares and Niinemets 2008). For instance, when light becomes a limiting resource, the lack of nutrients can reduce the ability of some species to simultaneously compete for light, magnifying the negative effect of shading. One prominent of shade-tolerant species is Urochloa brizantha, a perennial $\mathrm{C}_{4}$ grass species, which is well known as exhibiting high growth potential in integrated crop-livestock systems with trees (Fig. 5b). Overall, tolerance to simultaneous stresses is still poorly understood, despite of ubiquitous multiple stresses in nature (Valladares and Niinemets 2008). The state of the art presented so far clearly emphasizes the importance of gaining more conclusive insight into the species-dependent response to interactive light and nutrient availability gradients. Many studies of trait-based ecology have focused on aboveground traits. However, interactions between plant and soil, a belowground process, can have a strong impact on plant community structure (Bever et al. 2010). Root and plant litter traits, and traits mediating plant microbial interactions and how they are linked to plant soil interactions (e.g. see Ke et al. 2015) can provide more information about tolerance to multiple stresses, which is crucial in plant community ecology. Thus, further progress is still necessary.

\subsection{Intraspecific trait variability}

As highlighted above, plant functional traits have been extensively used to describe species strategies. Moreover, plant functional traits afford greater insight into the diverse ways through which plants adjust to changing environmental conditions. However, this functional response may be a deterministic component of species strategies, rather than passive plastic responses to an environmental gradient (Grassein et al. 2010). In other words, species adaptation to a new environment may evolve traits that vary among species strategies or trait values (i.e. species strategy indicators).

In addition to contrasting mean trait values between species, the strategy of a species could be further characterized by the variations in traits responses along environmental gradients (Albert et al. 2010). For instance, along an experimental productivity gradient, Grassein et al. (2010) observed that the exploitative species $D$. glomerata expressed an overall higher level of phenotypic plasticity (i.e. the capacity of a given genotype to render different phenotypic values for a given trait under different environmental conditions, see Valladares et al. 
2006 for a review) compared to the conservative species Festuca paniculata. This higher level of plasticity may allow the exploitative species to adapt finely to local environments in order to efficiently use the available resources. Therefore, different responses may occur to the same environmental change according to species strategies. However, for some traits, similar responses to the same environmental change may be observed, regardless of species strategies. For example, we can observe a decrease in specific leaf area with a decrease in the availability of nutrients, regardless of species strategies (Pontes et al. 2010). Hence, we can hypothesize that some traits are only environmental dependent. In summary, both trait values and intraspecific trait variability (or trait plasticity) can improve our understanding on the links between the dynamics of individual plants, communities and the ecosystem functioning (Suding et al. 2008). Therefore, according to Albert et al. (2010), although the intraspecific trait variability symptom does not affect generally the well-known functional trade-offs and strategies, its contribution to overall functional trait variability cannot be neglected. The same authors underline that the importance of intraspecific trait variability for key ecological questions will depend on the studied system and on selected traits and species, as well as on study objectives.

\section{Scaling up from species strategies to species abundance}

The functional diversity of trait values and strategies encountered between species within a given community can be linked with the overyielding at the ecosystem scale that results from the complementary in resource utilization between species (Zuppinger-Dingley et al. 2014). Overyielding is defined as the surplus of biomass yielded by an ecological community, compared to any of its members alone. In three grassland communities of six species, the authors of this review came to a similar conclusion based on the positive relationship between the functional diversity index calculated on four axes of functional specialization among grassland species (Fig. 3) and the complementarity effect (Fig. 6). On the other hand, the productivity and its inter-annual variation of grassland ecosystems are likely related with the community weighted value of plant height (Lavorel et al. 2011). Both community weighted trait and functional diversity indices used the abundance of each species within the community in their calculation (Loreau and Hector 2001; Botta-Dukàt 2005). In the aim to better predict ecosystem properties and services, a first step is then to better understand species assemblage and predict species abundance within and among communities.

\subsection{Community assembling rules: a brief review of niche-based processes}

As described above, identifying species strategies with their plant functional traits helps for understanding how species respond, i.e. adapt to abiotic conditions and survive. Consequently, the trait-based approach may contribute to explain patterns of species abundance and its distribution in plant communities. As such, the surrounding environment of species constitutes a filter which selects a range of trait attributes favouring species fitness, a process called environmental or habitat filtering (Keddy 1992; Díaz et al. 1998). Environmental filtering is the preferred term when only abiotic conditions are at play in the selection of species, while habitat filtering refers to both abiotic and biotic conditions (Maire et al. 2012a). For instance, along a fertility gradient in Mediterranean rangeland, plants with rapid growth and nutrient acquisition strategies were filtered out on shallow soils, while conservative and stress-tolerant strategies (small plants with thin leaves, low specific leaf area and low leaf nitrogen content; Grime 1977) were able to persist and cope with local nutrient and water shortages (Bernard-Verdier et al. 2012). As such, abiotic factors are usually considered to cause a selection in the range of trait attributes found within a community (Grime 2006).

In addition, environment may also act as a disruptive force when equal fitness in response to similar annually averaged abiotic constraints is reached by opposite functional strategies (Freschet et al. 2011). For instance, at the drought end of an aridity gradient in Mediterranean shrublands, stress avoidance strategy species exhibiting high specific leaf area and rapid growth coexist with species of very low specific leaf area and a tolerance strategy during a short rainy period (Gross et al. 2013a, b). Finally, in contrast to its deterministic role, the Hubbel's neutral theory predicts that environment does not constitute a force on the selection of species based on their trait attributes (Hubbell 2001). In such circumstances, species selection will only depend on immigration/species turnover probability rules that are not based on the species niche concept (Chave 2004).

Identifying species' strategies helps also understanding (i) how species are selected in a given environment, (ii) how they interact with their neighbour (competition vs. facilitation) and (iii) how they acquire their status/success within the community (dominant vs. subordinate species). Based on the comparison of trait attributes encountered within a given pool of species and a given habitat, two coexistence theories based on competition for resources between species have to be considered: the competitive hierarchy vs. niche differentiation. Although the former bases the dominance of species on their hierarchy of trait attributes (Kunstler et al. 2012; Fort et al. 2014), the latter bases species coexistence on the absolute difference between 


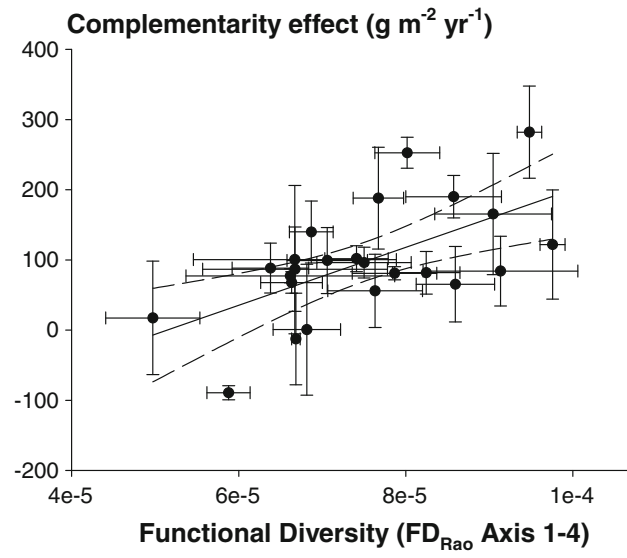

Fig. 6 Simple regressions between the functional diversity index FDrao (Botta-Dukàt 2005) and two components of the biodiversity effect: the selection and complementarity effects (Loreau and Hector 2001). FDrao is calculated using the species position along the four first axes of the principal component analysis presented in Fig. 3. The biodiversity effect is the surplus of production that a structured community achieved in comparison with the sum of individual productions that each species achieved in monoculture. The selection and complementarity effects distinguish the effects of very productive and dominant species to the

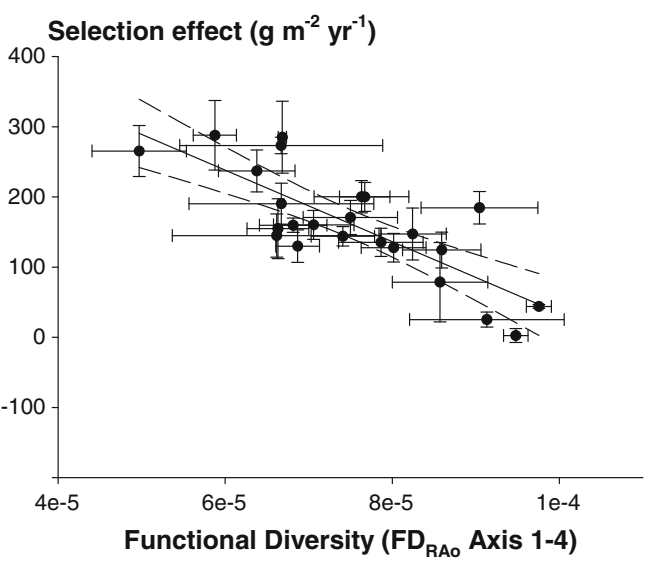

complementarity in resource utilization by different species. Three grassland communities of six grass species across four management treatments (two cut frequencies and two levels of nitrogen fertilization) and throughout 2 years were explored in this study $(n=24)$. Error bars represent the variability for a given community between the three blocks of repetition (see Pontes et al. 2012 for details on the experimental design). Details on linear equations: Complementarity effect: $Y=41.3$. $10^{3}\left( \pm 11.5 \cdot 10^{3}\right) \times X-2.12( \pm 0.88), P<0.01, r^{2}=34.4$; Selection effect: $Y=-50.1 \cdot 10^{3}\left( \pm 8.4 \cdot 10^{3}\right) \times X+5.4( \pm 0.6), P<0.001, r^{2}=60.9$ species trait attributes (MacArthur and Levins 1967). Related to these two processes, most recent theories define, respectively, two kind of traits for species coexistence: the ones that promote the difference in species fitness ("fitness difference trait") and the ones that promote the stabilization of niche differences and species coexistence ("niche difference trait") (Levine and HilleRisLambers 2009; Mayfield and Levine 2010; HilleRisLambers et al. 2012).

For example, productive meadows tend to be dominated by tall, fast growing species (Louault et al. 2005) that can develop a disproportionately large competitive effect on local resources (e.g. light and nutrient, Grime et al. 1997). Competitive hierarchy is then a convergent force that shapes a skew distribution of trait attributes towards one value, where several dominant species might coexist as equilibrating inter-specific relative to intra-specific interactions (Murrell 2010). Importantly, competitive hierarchy acts as a habitat filter by excluding less competitive species, and can so be considered as the biotic part in the habitat filtering process (Grime 2006; Mayfield and Levine 2010; Kunstler et al. 2012). On the other hand, niche differentiation is a selective force that may favour species coexistence by limiting similarity in resource use in space and time and therefore, competitive exclusion between species (MacArthur and Levins 1967; Pacala and Tilman 1994). By increasing trait attribute dissimilarity, niche differentiation forces the distribution of trait attribute towards large plateau and bimodal distributions.

Assembling rules are usually examined through the lens of convergence and divergence observation of trait attributes along gradients, which have constituted an important first step towards studying community assembly (Kraft et al. 2008). However, we see that convergence and divergence can result from both abiotic and biotic interactions. Disentangling their relative contributions in structuring community may be considered as an important step towards achieving a better understanding and prediction of community assembly (Gross et al. 2013a, b).

\subsection{Which traits for which assembly process?}

Species are represented by a collection of plant functional traits characterizing an organ's (root, stem, leave, flower, seed) or a whole-plant's property (plant height, life history), which characterize a plant function (e.g. nutrient absorption, water transport, gas exchange, sexual reproduction, dispersal, competition for light, lifespan) (Violle et al. 2007). Some traits are related along axis of specialization leading to redundant information for characterizing species strategy, but some others are not. Laughlin and Laughlin (2013) define the intrinsic dimensionality of plant traits as "the minimum number of independent axes of variation that adequately describes the functional variation among plants and is therefore a fundamental quantity in comparative plant ecology". While these authors show with data reduction methods that four dimensions are necessary to describe the variance of large collection of traits, most studies in functional ecology only describe two-to-three dimensions in trait collection.

Each dimension of the trait space is potentially independent of another and may be the place of a different selection process 
for species assembling (Mason et al. 2011; Spasojevic and Suding 2012; Gerhold et al. 2013; Laliberté et al. 2013; Price et al. 2014; Carboni et al. 2014). For instance, along an environmental severity gradient in productive grassland communities, Maire et al. (2012a, see also Bernard-Verdier et al. 2012 as another example along a natural soil fertility gradient in Mediterranean rangelands) found that convergence pattern towards high plant stature traits was the predominant force to explain species abundance in fertile and less disturbed habitat. However, this force decreased continuously in its importance towards poorer and more disturbed habitats. On the opposite, the divergence between species for leaf traits linked with the leaf economic spectrum became more and more important to explain species abundance along the environmental severity gradient. Furthermore, trait convergence and divergence were observed on independent dimensions representing root preferences for different forms of mineral $\mathrm{N}$ in soil and life-history, and so played a significant role to explain the structure of these productive grasslands. A good example of this is the third PCA axis on Fig. 3, which opposed root uptake capacity for nitrate vs. ammonium, reflecting the trade-off between the investments in root $\mathrm{NO}_{3}{ }^{-}$vs. $\mathrm{NH}_{4}{ }^{+}$transporters. In Fig. 7, we observe that trait convergence (i.e. inferred by plant functional traits) and trait divergence (i.e. inferred by functional dissimilarity, FD) explained, on average, 69 and $31 \%$ of the variance, respectively. However, these results depended on the management conditions. It is another important conclusion from all these findings that trait convergence explains less variance as environmental severity increases, due an increased number of available niches for plants to coexist (Maire et al. 2012a).

By leading either to trait convergence or trait divergence, assembling processes may be considered as mutually exclusive. But, the intrinsic multidimensionality of traits makes the coexistence of these two patterns within a given community possible. It has yet to be explored if a given trait is more likely a subject to convergence or divergence pattern and can further be defined as "fitness difference trait" (equalizing dominance) or "niche difference trait" (stabilizing coexistence).

\subsection{Which assembly process for which conditions?}

Trait convergence and divergence patterns have been recently shown to be dependent on the spatial scale at which species assembling is observed (Kraft and Ackerly 2010; Freschet et al. 2011; Dengler et al. 2014). Earlier theories propose a continuum along which the assembling of species is determined by stochastic events (e.g. dispersal limitation) at large spatial scale (landscape, $\left.\mathrm{km}^{2}>\right)$, while at more local scale $\left(\mathrm{m}^{2}-\right.$ $\mathrm{km}^{2}$ ) deterministic processes are ruling species assemblage (Lortie et al. 2004; Gravel et al. 2006). In dry semi-natural grassland in south-western Sweden, this pattern was effectively observed among a series of leaf and whole-plant traits

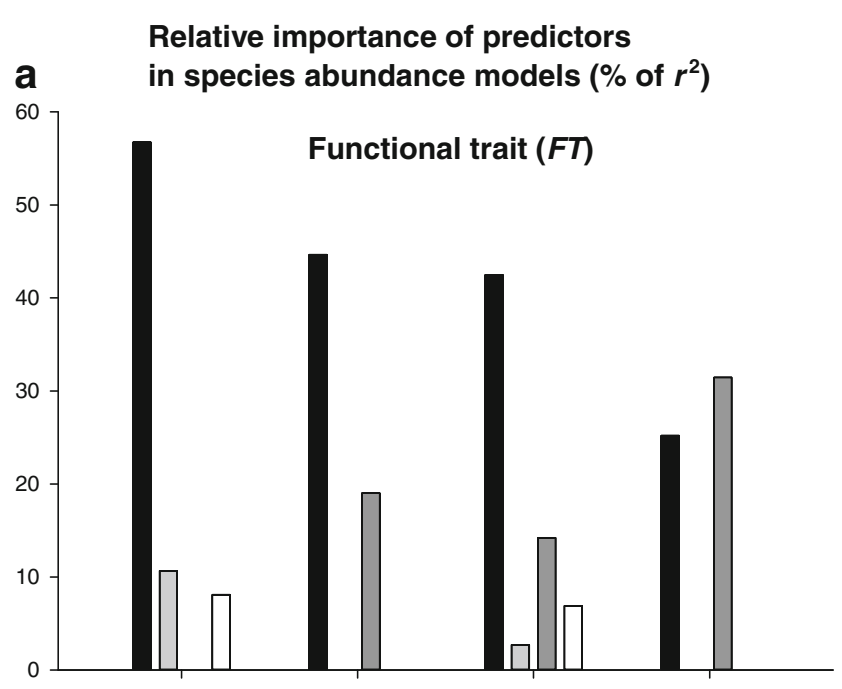

b

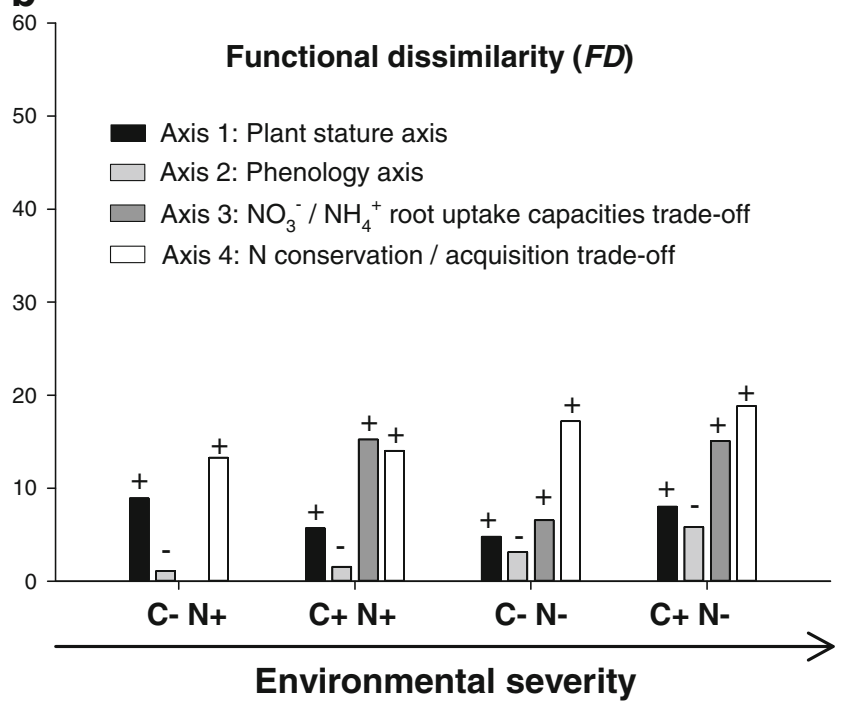

Fig. 7 Importance of a functional trait and $\mathbf{b}$ functional dissimilarity values to explain species abundance in three communities of six species. The importance is assessed from the relative amount of variance explained (\% of $\left.r^{2}\right)$ by each variable selected in the regression models (see Maire et al. 2012b). Independent variables investigated: plant stature, growth precocity, root uptake preference for nitrate and ammonium, plant strategy for $\mathrm{N}$ acquisition and conservation (see Fig. 3). In b, plus sign indicates a positive relationship between species functional dissimilarity and abundance (indicating niche differentiation), whereas minus sign indicates a negative relationship (indicating habitat filtering). Note that a missing bar indicates that a variable was not retained in the final model. We ranked each experimental treatment based on environmental severity (measured by standing biomass and leaf nitrogen content). $\mathrm{C}-$, three cuts per year; $\mathrm{C}+$, six cuts per year; $\mathrm{N}-$ and $\mathrm{N}+$ representing 12 and $36 \mathrm{~g} \mathrm{~N} \mathrm{~m}^{-2}$ year ${ }^{-1}$, respectively. FT and FD indices were used to infer the effect of habitat-filtering and niche differentiation processes on species abundance, respectively

comparing landscape scales with patch scales (de Bello et al. 2013). In addition, these authors observed for this series of traits clear patterns of convergence at a patch scale and divergence at a smaller spatial scale (neighborhood, $\mathrm{cm}^{2}-\mathrm{m}^{2}$ ), 
which is, according to the authors, in agreement with the theoretical pattern, predicting "a shift from biotically-driven divergence to abiotically-driven convergence with increasing spatial scale of observation" (Weiher and Keddy 1995; Holdaway and Sparrow 2006).

Similarly to the spatial scale, the pattern of convergence and divergence has been theorized to depend on the severity of environment. At harsh conditions (e.g. cold or dry), strong abiotic filtering is expected as few species are able to physiologically cope with, while niche differentiation is expected in more competitive and productive habitats according to the limiting similarity hypothesis (Weiher et al. 1998; Cornwell et al. 2006). In agreement with these expectations, Price et al. (2014) found less niche overlap on specific leaf area within Estonian artificial grasslands under high fertility treatment. By contrast, the opposite pattern was found for leaf size and plant height. These expectations contrast also with a long-term study (Harpole and Tilman 2007), where they found that increasing environmental severity increased the number of available niches for plants to coexist. In productive grassland, niche differentiation and habitat-filtering are continuously observed among traits along a gradient of environmental severity, with niche differentiation alone being overall more important under harsher conditions (Maire et al. 2012a).

As underlined earlier, it is however difficult to relate the patterns of trait convergence and divergence to the relative importance of niche-based assembling rules (habitat filtering and niche differentiation can both lead to convergence and divergence trait pattern). Here, we propose in future studies to consider multiple spatial scales in combination with the multi-dimensionality of traits to better associate trait patterns with assembling rules (see Gross et al. 2013a, b as an example).

Similarly to traits, environment is also intrinsically multidimensional. At regional scales, soil $\mathrm{pH}$ co-varies strongly with precipitation, while soil texture is mostly independent of soil pH (Jenny 1941). Considering the independent dimensions of environment will also help to better understand the different selection forces for plant functional traits. For instance, leaf nitrogen content increases both with soil fertility and climatic aridity (Maire et al. 2015). In grasslands, the herbivory pressure and the management can be considered as additional dimensions of the environment to which species will respond. However, most of the studies in community ecology are based on a unique environmental dimension (e.g. aridity, nutrient, temperature, altitude), while considering different environmental variables has been shown to improve species abundance distribution (Dubuis et al. 2012). Identifying and considering the multidimensionality of the environment and quantifying how each environmental dimension impact each trait dimension are important steps towards predicting the structure of communities in a more consistent way.

\subsection{Which assembly process for which status in the community?}

From the abundance that species can achieve in a given community, Whittaker (1975) defines three statuses: the dominant species, which are usually few in a community and constitute a high proportion of its biomass; the subordinate species which are usually more in number than dominant and which belong to a given extend to the same vegetation association than the dominant ones and provide a lower contribution to the community biomass; and the transient/rare species which vary in number, differ strongly in their trait from dominant and subordinate species and make a very small contribution to the community biomass (Grime 1998).

The different niche-based processes are likely to promote each of these statuses, but the importance of each process for each status has not been clearly investigated yet. The abundance of dominance species has been well predicted by applying the habitat-filtering process (Shipley et al. 2006; Laughlin et al. 2012). Selecting for an optimal trait attribute in order to cope with environmental conditions, the habitat-filtering process considers that the species exhibiting this attribute will achieve high fitness and be dominant within the community. On the other side, species exhibiting a trait attribute far from the optimum defined by the environment will be less viable and achieve more likely a subordinate or rare status. As such, habitat-filtering is a process which favours the dominance of species.

On the opposite, niche differentiation is expecting to favour the coexistence of rare species together with dominant species. By artificially increasing the importance of niche differentiation, Maire et al. (2012a) have shown that rare species are promoted within virtual productive grassland communities through both the increase of the community evenness and the prevention of rare species exclusion. In these grassland communities, rare species benefited from a higher biomass per individual in a community as compared to their monoculture (Fig. 8). This effect is dynamic, so that species' per capita growth rates decline as a rare species become dominant within communities. This pattern is the signature of the negative frequency dependence (Adler et al. 2007), which allows stabilizing the coexistence of species when the strength of interspecific interactions is lower than that of intra-specific interactions (Chesson 2000; Levine and HilleRisLambers 2009; Murrell 2010). In addition to the former competition-based process of species stabilization, facilitation is also able to promote the coexistence of subordinate to rare species with dominant species within a community. For instance, Gross et al. (2013a) observed that facilitation interplayed with an aridity gradient to enhance subordinate and rare species and the biodiversity of semi-arid Mediterranean shrublands. All together, niche-based processes may jointly operate in a given community promoting different statuses of species. However, this 
Fig. 8 Relationship between species abundance (log scale) and species overyielding among three different grass communities of six species across the four management conditions. Positive overyielding points to species $i$ that produced more biomass in mixture $j$ than in monoculture stands, while negative overyielding points to species $i$ that produced less biomass in mixture $j$. Each colour represents a species. Details on linear regression equation including all species: $Y=-0.16^{* * *} \cdot \log (\mathrm{Ab})-$ $0.04^{\mathrm{ns}}, P<0.001, r^{2}=0.41$. Adapted from Maire et al. (2012b). See Fig. 3 for species codes

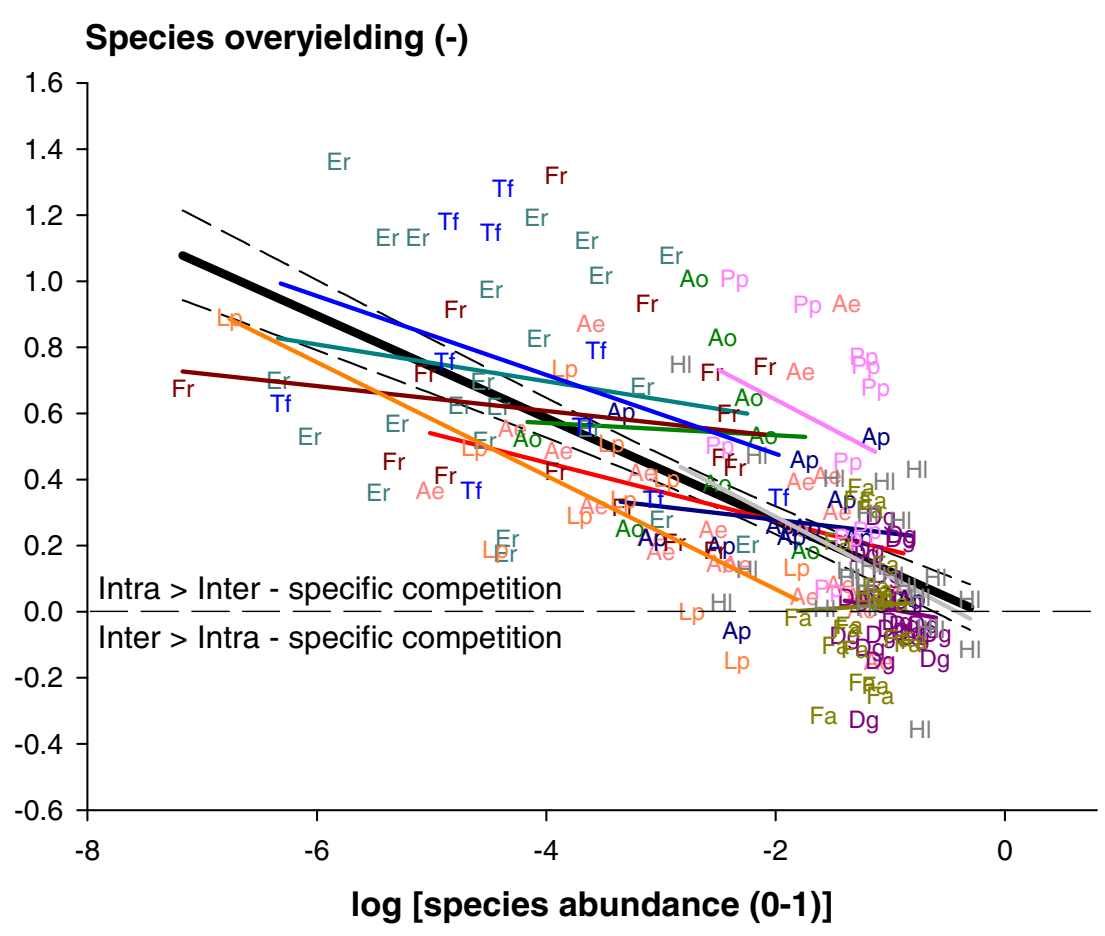

assumption still needs to be verified and quantified along a larger spectrum of communities.

\subsection{From empirical to predictive approach}

In order to better understand the optimal strategies that species used to respond to a changing environment and the consequences on the plant fitness (growth, survival and reproduction), modelling approaches with individual-based models are crucial (Martineau and Saugier 2007; Tomlinson et al. 2007; Lazzarotto et al. 2009; Soussana et al. 2012; Maire et al. 2013a, b, as examples for grasslands). Describing the physiological, morphological and demographic mechanisms that respond to resource availability, population density dependence and neighbour frequency dependence (which are three fitnesslimiting factors according to McNickle and Dybzinski 2013), such approaches adequately simulated for plant and population plasticity and species interactions (Lazzarotto et al. 2009; Maire et al. 2013b). It is then possible to look for the appropriate trait delineating the optimal species/population strategy in response to single or several management factors in interaction (Maire et al. 2013a), likely accounting for all other aspects that the trait can select according to the "mysterious laws of the correlation of growth" (Darwin 1859). However, such individual-based modelling approaches are quite parameter-consuming and may be limited to a small pool of crop species. Other approaches may be more appropriate to scale up from species strategies to species abundance among communities and along environment/management gradients.
Two niche trait-based models based on two different mathematical approaches have been proposed in order to predict the relative abundance of species from a regional species pool based on the habitat filtering process (Shipley 2009; Laughlin et al. 2012). The "Maxent model" (for maximum entropy also called the "CATS model": "community assembly by trait selection") has been developed by Shipley (Shipley et al. 2006; Shipley 2009). It uses a matrix of species trait means and a vector of predicted communityweighted mean traits as input to obtain the most even probability distribution of species relative abundance. It has been shown in several studies how significant variation in species abundances can be explained (Sonnier et al. 2010; Merow et al. 2011; Laliberté et al. 2012). The second model, entitled "Traitspace", has been proposed by Laughlin (Laughlin et al. 2012; Laughlin and Laughlin 2013; Laughlin 2014). It is based on a hierarchical Bayesian approach. As input, it investigates how individual-level trait attributes are distributed along an environmental gradient and predicts probabilities of the occurrence for each species. As such, the Traitspace model incorporates intraspecific trait variation and does not require abundance information as input. Recently, the Traitspace model has proposed to include niche differentiation by considering bimodal distribution of individual-level trait attributes for each level of the environmental condition (Laughlin et al. 2015). Both of these traitbased models are generalizable to any ecosystem and can theoretically accommodate any number of species, traits and environmental conditions. 
As an example of the Traitspace model, the authors have used the data of Maire et al. (2012a) for this review to predict the abundance of five species within a grassland community along a gradient of environmental severity, the latter composed by a mix of nutrient fertilization and cutting frequency. We have used two plant functional traits, leaf nitrogen content and plant elongated height responding to the environmental gradient (Fig. 9a, b), which appears as two response traits: leaf nitrogen content for response to fertility and plant height for response to disturbance. These traits showed different distributions among species (Fig. 9c, d). We have found that the model was able to reproduce the average trend of abundance distribution along the environmental severity gradient (Fig. 9e, f). However, the model over-predicts the abundance of dominant species and under-predicts the abundance of rare species. In such communities, the role of asymmetric competitive hierarchy for light has been shown determinant to explain the outcome of biotic interaction (Soussana et al. 2012) but is not a mechanism included in the model. In addition, only two traits (defining two independent axes of specialization) were used here for simplicity reason, while in Maire et al. (2012a), four traits were necessary to achieve reliable prediction of grassland species assembly. In Laughlin and Laughlin (2013), four to eight traits were required to accurately predict the structure of different biotic communities. In conclusion, several traits, ideally belonging to different functional axes of specialization, are necessary to better predict the structure of communities.

These two probabilistic models are powerful by their simplicity, despite their inherent formalization complexity, as they only require a small set of parameters. They also represent an important step towards evaluating the predictive power in different ecosystems, of different species and different environmental and management conditions. Using two conceptual approaches, the utilization of both models is important for achieving the aim of species abundance prediction. However, the Traitspace model seems to be the most powerful as it accounts for intraspecific trait variation and niche differentiation and does not use abundance information to be calibrated.

Such niche-based model can be complemented by another theoretical approach, the one consisting of the prediction of the average trend of plant functional traits as a function of the environment, which is an input to niche-based models. For instance, the optimal leaf size can be predicted using a mass-energy balance equation (Givnish 1978), leaf nitrogen content and the maximal carboxylation capacity as a function of radiation and temperature (Maire et al. 2012b; Prentice et al. 2014) as well as stomatal conductance as a function of the vapour pressure deficit (Medlyn et al. 2011). As such, the calibration of trait-environment relationship in Maxent and Traitspace models may be derived from this theoretical approach. However, the calibration of the distribution of trait variation within a given environment is poorly
Fig. 9 Application of the Traitspace model to predict the abundance of a grass community of five species along an environmental severity gradient. Only two traits were chosen for simplicity: leaf nitrogen content and plant height. The environmental severity gradient has been established through four experimental treatments mixing two disturbance frequencies and two fertilization levels. Level 1: 3 cuts year $^{-1}, 36 \mathrm{~g} \mathrm{~N}$ $\mathrm{m}^{-2}$ year $^{-1}$; Level 2: 6 cuts year $^{-1}, 36 \mathrm{~g} \mathrm{~N} \mathrm{~m}^{-2}$ year $^{-1}$; Level 3: 3 cuts year ${ }^{-1}, 12 \mathrm{~g} \mathrm{~N} \mathrm{~m}^{-2}$ year $^{-1}$; Level 4: 6 cuts year $^{-1}, 12 \mathrm{~g} \mathrm{~N}$ $\mathrm{m}^{-2}$ year ${ }^{-1}$. First, an independent calibration procedure was processed: a, b we determined the relationship existing between individual trait attributes (including all five species) and the environment observed in the monocultures of the five grass species. This first calibration included both the average trends as well as the prediction interval, accounting for the variance around this response. c, d A second calibration concerned the location of each species in a trait space through Gaussian mixture models accounting for the multidimensionality of the species niche. Similarly to environment, this calibration accounted for the intraspecific trait variation. e, f Secondly, an inference procedure using Bayes' theorem allowed predicting the abundance of species within a community including these five grass species. Knowing the environment, we can know the probability of the trait attribute selected by the environment. Knowing the probability of the trait attribute in a given environment as well as the probability that a given species has this trait attribute, it is possible to predict the probability of species abundance. See Fig. 3 for species codes

understood theoretically and may constitute an interesting avenue to explore.

Another good example of how the functional trait approach allows us to model the growth of mixed swards is given by Duru et al. (2009). They aggregated sets of plant functional traits to plant functional types and simulated production of grassland vegetation consisting of different percentage contributions of these types. It is obvious that modelling growth in a species-rich community based on performance of individuals, thereby considering interspecific competition, will be unwinnable. The functional trait approach, however, allows aggregating species and strategies and so leads to an enormous reduction in primary data and related uncertainty, which would not have been possible based on taxonomy. This procedure also stems on the premise that the trait-based approach can best explain functional relationships between processes and functions in plants with the environment.

\section{Perspectives in plant functional strategies}

\subsection{Enlarged drivers and traits to define plant strategies}

Above-ground traits have been mainly considered in the identification of plant grass strategies, but root traits, despite methodological aspects, become more often studied and need further attention. They have the potential to identify grass strategies. For instance, morphological roots traits appears as valuable indicators of environmental change (mowing, fertilization, Leuschner et al. 2013), which in 

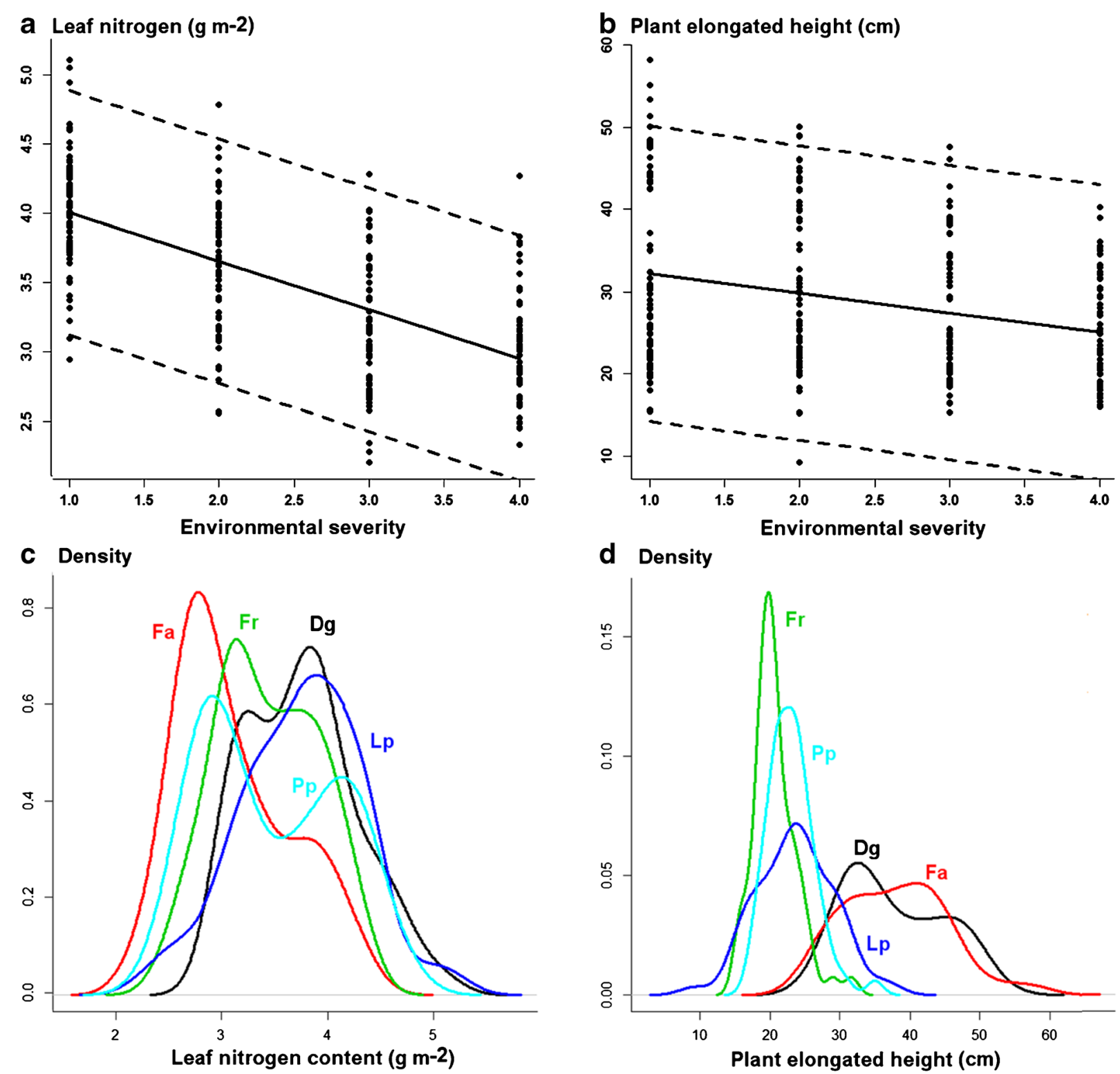

e Predicted relative abundance (0-1)
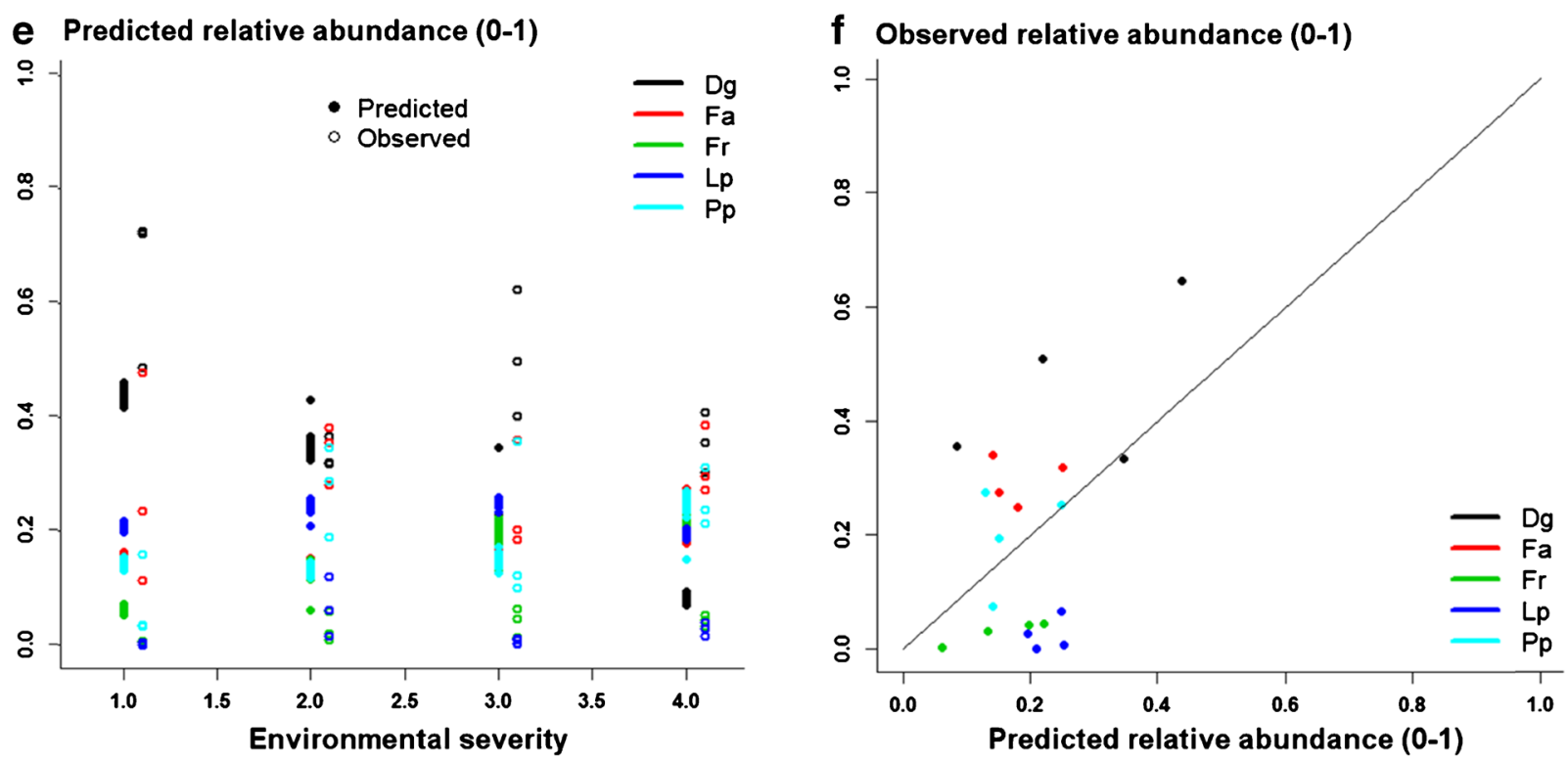
turn could rank grass species along gradients, such as from conservative-strategy to acquisitive one with, respectively, deep and coarse root system or shallow and thin root system (Fort et al. 2013), or also could discriminate for drought tolerance (Craine et al. 2012) or dehydration avoidance (Zwicke et al. 2015). Going further on roots traits appears also promising in order to better understand below-ground processes as shown by recent studies (see Ke et al. 2015; Legay et al. 2014; Grigulis et al. 2013).

\subsection{Predicting the optimal shift of traits in response to ongoing environment/management change using individual-based modelling}

Plant functional traits have turned to be an essential tool to study and understand the strategies that plant species used to adapt to conditions along gradients of management/ environment and to coexist with neighbours within communities (McGill et al. 2006; Violle et al. 2007; Garnier and Navas 2012). Some early and recent theories based on optimality principles have permitted to evaluate the optimal values that traits should have to maximize the $\mathrm{C}$ return or to minimize the loss of energy in function of the surrounding environment (Givnish 1978 for leaf size; Kikuzawa et al. 2013 for specific leaf area and leaf lifespan; Maire et al. 2012b for leaf nitrogen content; McMurtrie et al. 2012 for root distribution; Medlyn et al. 2011 for stomatal conductance; Prentice et al. 2014 for the ratio of internal $\mathrm{CO}_{2}$ concentration to atmospheric $\mathrm{CO}_{2}$ concentration). Other theories based on evolutionary games include biotic interactions to estimate the optimal trait value (e.g. Falster et al. 2008 for plant height). However, only few models consider physiology, morphology as well as demographic processes in the calculation of optimal trait values (Marks and Lechowicz 2006; Falster et al. 2011; Soussana et al. 2012). In the context of grasslands where management is an important driver of vegetation dynamics interfering with the prediction of optimality in function of environment only, there is a large avenue to better predict the optimality of traits, i.e. to which trait value species should converge to dominate the communities.

\subsection{Going through the debate of opposing niche-based theories}

Since the popularized work of MacArthur on limiting similarities (1964; MacArthur and Levins 1967), there is an intense debate on which of the niche-based processes is the best to explain the pattern of species abundance (Laliberté et al. 2014). Most of the work done on that area used a top-down approach that compares observed community-level trait distribution to null model predictions derived from randomly assembled null communities compiled from a regional pool of species (e.g. Emerson and Gillespie 2008; Jung et al. 2010).
If co-occurring species are more or less similar than expected by chance, a given niche process is suggested to play the structuring role of the community. Such exclusive statistical procedure does not permit to detect mechanisms of compensation between processes along a given dimension of functional specialization and mechanisms of addition with different processes playing on independent dimensions of functional niche. However, it is more and more observed that not a single but several niche-based processes interact concomitantly to explain the structure of communities (Grime and Pierce 2012). Hence, there is an important toolkit to develop in the next future to better detect where and how much each of the niche-based process occur within and among communities, especially in grassland where drivers of environment and management can be plural. An example for such novel approach was proposed by Gross et al. (2013a, b).

\subsection{Distribution of traits within a species and a given environment and the delineation of species regional pool}

In the Traitspace model (Laughlin et al. 2012) and in empirical studies (Albert et al. 2010), the distribution of trait values encountered for a species and in a given environment is an important parameter to better understand the community assembling. However, in comparison with the optimal values that traits should achieve to dominate a community (see paragraph 4.2), there are very few research on potential distribution of trait values within species and within communities. For instance, according to Niinemets (2015), more common garden experiments in different parts of a species bioclimatic distribution are needed to gain an insight into the ecotypic vs. plastic sources of variation in species bioclimatic responses.

As previously developed, the regional pool of species is currently used to observe the assembling patterns of communities. However, most of the time, the regional pool is simply the collection of species that is observed along the studied gradient. Using this regional pool as a parameter, ecologist can predict the assembling of plant communities. However, there are very few discussions on how to predict the original composition of species. Future studies should investigate how theoretical prediction of the regional species pool could be achieved based, for example, on the assessment of the occupied functional space that could be calculated from functional traits (Violle and Jiang 2009).

\subsection{Achieving functional target in grassland ecosystems by theory-driven ecological management}

The work of Laughlin (2014) on ecological restoration can be directly transferred for grassland management purposes. In grasslands, functional targets are multiple (fodder production, fodder quality for livestock nutrition and milk quality, soil C 
storage, preservation of patrimonial/endangered species, biodiversity) and drivers too (environment, climatic extremes, management including cutting, grazing, fertilization as well as recreational activities). Experimental studies have yet been done to investigate whether plant mixture through complementarity in resource acquisition could enhance grassland ecosystem function; nevertheless, species were most of the time chosen according to low number of functional traits or plant types (for example, shallow- and deep-rooted cross with legume or non-legume species to test for drought resistance (Hoekstra et al 2015), temporal development with fastestablishing or temporally persistent species cross with nitrogen acquisition type, i.e. legume or non-legume species, to test for biomass production (Finn et al 2013)). Thus, it appears important to benefits from tools to help for the identification of species assemblages for specific objectives. To achieve such functional targets, Laughlin argues that it is now possible to manipulate community assemblages following the quantitative combination proposed by the "Traitspace" model (Laughlin 2014) and the response-and-effect trait theory (Suding et al. 2008). Based on niche-based processes (environmental filtering and niche differentiation), trait identity, trait value and species assemblage may be theoretically determined for achieving resilient and functional grassland ecosystems. In a rapidly changing world, such framework promises very interesting future research for efficiently adapting grassland management but needs now to be tested.

\section{Conclusions}

Grassland is an important resource for the livestock sector and for various ecological services. An increase in species richness often - but not always - leads to benefits in terms of ecosystem services, including productivity, and its lower variance (e.g. Polley et al. 2013). Consequently, semi-natural grasslands and other botanically diverse ecosystems have attracted increased interest, both from a need to reduce costs of production and because of increased concern about the quality of the environment and of agricultural products derived from it. The trait approach contributes to the simplification of floristic complexity on grassland. In others words, identifying species strategy based on their functional traits improve our understanding of how species respond to their environment, i.e. adapt and survive to abiotic conditions, and also how species affect local resources. Further, the intensity of management and utilization, and the production of goods and various services at a given site from grasslands are increasingly affected by economic, sociopolitical, scientific and technological developments and most importantly by the impacts of climate change. Therefore, information on traits may be a more objective predictor of changes in vegetation in response to global change drivers than, for example, species identity or functional groups (McGill et al. 2006). However, further progress is still necessary for the development of trait databases. Efforts are also required for an inter-disciplinary research including taxonomy, ecology, ecophysiology and grassland science, posing more complex questions such as which trait expression and variability best predicts species abundance and coexistence within communities, and which traits affect processes, properties and services at the ecosystem level (de Bello et al. 2010; Garnier and Navas 2012; Maire et al. 2012a; Schellberg and Pontes 2012). For instance, the long-term objective of predictive approaches like Traitspace and Maxent would be to determine species assemblages according to ecosystem properties or targeted services (carbon storage, productivity, resilience, etc.). In addition, most studies in community ecology are based on one single environmental dimension (e.g. aridity, nutrient, temperature, altitude). We can expect that the insertion of environmental variable effects on multiple processes involved in species assembling will add further progress when scaling from the individual species to higher levels of organization.

The trait-based approach enables us to assess the interaction between plants and their environment simultaneously on a large number of species. Consequently, it allows a better understanding on species distribution, community assembly and ecosystem functioning (Garnier and Navas 2012). Therefore, increasing the applicability of trait-based tools to different agricultural situations will certainly improve our skills for the management of more diverse and complex grasslands in a changing world. This also includes the application of the principles of the trait approach to other disciplines. Especially for interactions of plants with the soil, a similar approach for soil traits would be very useful. "Soil functional traits" such as $\mathrm{pH}$ value, bulk density, nutrient content and water holding capacity have yet not been fully integrated into the trait theory, although they are often considered as being very important for the trait syndrome of grassland.

Acknowledgments The authors are grateful to Jean-François Soussana and Pascal Carrère, as well as all INRA-UREP team for the support on traits' experiment at Clermont-Ferrand. Jürgen Schellberg gratefully acknowledges financial support from the German Research Foundation (DFG) through project no. SCHE 549/2-1.

\section{References}

Adler PB, HilleRisLambers J, Levine JM (2007) A niche for neutrality. Ecol Lett 10:95-104. doi:10.1111/j.1461-0248.2006.00996.x

Al Haj Khaled R, Duru M, Theau JP, Plantureux S, Cruz P (2005) Variations in leaf traits through seasons and $\mathrm{N}$-availability levels and its consequences for ranking grassland species. J Veg Sci 16: 391-398. doi:10.1111/j.1654-1103.2005.tb02378.x

Albert CH, Thuiller W, Yoccoz NG, Douzet R, Aubert S, Lavorel S (2010) A multi-trait approach reveals the structure and the relative 
importance of intra- vs. interspecific variability in plant traits. Funct Ecol 24:1192-1201. doi:10.1111/j.1365-2435.2010.01727.x

Arredondo JT, Schnyder H (2003) Components of leaf elongation rate and their relationship to specific leaf area in contrasting grasses. New Phytol 158:305-314. doi:10.1046/j.1469-8137.2003.00745.x

Bernard-Verdier M, Navas ML, Vellend M, Violle C, Fayolle A, Garnier E (2012) Community assembly along a soil depth gradient: contrasting patterns of plant trait convergence and divergence in a Mediterranean rangeland. J Ecol 100:1422-1433. doi:10.1111/ 1365-2745.12003

Bever JD, Dickie IA, Facelli E, Facelli JM, Klironomos J, Moora M, Rillig MC, Stock WD, Tibbett M, Zobel M (2010) Rooting theories of plant community ecology in microbial interactions. Trends Ecol Evol 25:468-478. doi:10.1016/j.tree.2010.05.004

Botta-Dukàt Z (2005) Rao's quadratic entropy as a measure of functional diversity based on multiple traits. J Veg Sci 16:533-540. doi:10. 1111/j.1654-1103.2005.tb02393.x

Briske D (1996) Strategies of plant survival in grazed systems: a functional interpretation. In: Hodgson J, Illius AW (eds) The ecology and management of grazing systems. CAB International, Wallingford, pp 37-67

Carboni M, de Bello F, Janeček Š, Doležal J, Horníka J, Lepš J, Reitalud T, Klimešová J (2014) Changes in trait divergence and convergence along a productivity gradient in wet meadows. Agric Ecosyst Environ 182:96-105. doi:10.1016/j.agee.2013.12.014

Chave J (2004) Neutral theory and community ecology. Ecol Lett 7:241253. doi:10.1111/j.1461-0248.2003.00566.x

Chesson P (2000) Mechanisms of maintenance of species diversity. Annu Rev Ecol Syst 31:343-366. doi:10.1146/annurev.ecolsys.31.1.343

Cornelissen JHC, Lavorel S, Garnier E, Díaz S, Buchmann N, Gurvich DE, Reich PB, ter Steege H, Morgan HD, van der Heijden MGA, Pausas JG, Poorter H (2003) A handbook of protocols for standardised and easy measurement of plant functional traits worldwide. Aust J Bot 51:335-380. doi:10.1071/BT02124

Cornwell WK, Schwilk LDW, Ackerly DD (2006) A trait-based test for habitat filtering: convex hull volume. Ecology 87:1465-1471. doi: 10.1890/0012-9658(2006)87[1465:ATTFHF]2.0.CO;2

Craine JM, Berin DM, Reich PB, Tilman DG (1999) Measurement of leaf longevity of 14 species of grasses and forbs using a novel approach. New Phytol 142:475-481. doi:10.1046/j.1469-8137.1999.00411.x

Craine JM, Ocheltree TW, Nippert JB, Towne EG, Skibbe AM, Kembel SW, Fargione JE (2012) Global diversity of drought tolerance and grassland climate-change resilience. Nat Clim Chang 3:63-67. doi: 10.1038/nclimate 1634

da Pontes LS, Soussana JF, Louault F, Andueza D, Carrere P (2007) Leaf traits affect the above-ground productivity and quality of pasture grasses. Funct Ecol 21:844-853. doi:10.1111/j.1365-2435.2007. 01316.x

da Pontes LS, Louault F, Carrère P, Maire V, Andueza D, Soussana J-F (2010) The role of plant traits and their plasticity in the response of pasture grasses to nutrients and cutting frequency. Ann Bot 105: 957-965. doi:10.1093/aob/mcq066

da Pontes LS, Maire V, Louault F, Soussana JF, Carrère P (2012) Impacts of species interactions on grass community productivity under contrasting management regimes. Oecologia 168:761-771. doi:10. 1007/s00442-011-2129-3

Darwin C (1859) On the origin of species by means of natural selection, or the preservation of favoured races in the struggle for life. John Murray, London

de Bello F, Lavorel S, Díaz S, Harrington R, Cornelissen JHC, Bardgett RD, Berg MP, Cipriotti P, Feld CK, Hering D, Martins da Silva P, Potts SG, Sandin L, Sousa JP, Storkey J, Wardle DA, Harrison PA (2010) Towards an assessment of multiple ecosystem processes and services via functional traits. Biol Conserv 19:2873-2893. doi:10. 1007/s10531-010-9850-9 de Bello F, Vandewalle M, Reitalu T, Lepš J, Prentice HC, Lavorel S, Sykes MT (2013) Evidence for scale- and disturbance-dependent trait assembly patterns in dry semi-natural grasslands. J Ecol 101: 1237-1244. doi:10.1111/1365-2745.12139

Del-Val E, Crawley MJ (2005) Are grazing increaser species better tolerators than decreasers? An experimental assessment of defoliation tolerance in eight British grassland species. J Ecol 93:1005-1016. doi:10.1111/j.1365-2745.2005.01011.x

Dengler J, Janišová M, Török P, Wellstein C (2014) Biodiversity of Palaearctic grasslands: a synthesis. Agric Ecosyst Environ 182:114. doi:10.1016/j.agee.2013.12.015

Devictor V, Clavel J, Julliard R, Lavergne S, Mouillot D, Thuiller W, Venail P, Villegé RS, Mouquet N (2010) Defining and measuring ecological specialization. J Appl Ecol 47:15-25. doi:10.1111/j. 1365-2664.2009.01744.x

Devkota NR, Kemp PD, Hodgson J, Valentine I, Jaya IKD (2009) Relationship between tree canopy height and the production of pasture species in a silvopastoral system based on alder trees. Agrofor Syst 76:363-374. doi:10.1007/s10457-008-9192-8

Díaz S, Cabido M, Casanoves F (1998) Plant functional traits and environmental filters at a regional scale. J Veg Sci 9:113-122. doi:10. $2307 / 3237229$

Díaz S, Noy-Meir I, Cabido M (2001) Can grazing response of herbaceous plants be predicted from simple vegetative traits? J Appl Ecol 38:497-508. doi:10.1046/j.1365-2664.2001.00635.x

Díaz S, Hodgson JG, Thompson K et al (2004) The plant traits that drive ecosystems: evidence from three continents. J Veg Sci 15:295-304. doi:10.1111/j.1654-1103.2004.tb02266.x

Díaz S, Lavorel S, McIntyre S et al (2006) Plant trait responses to grazing - a global synthesis. Glob Chang Biol 12:1-29. doi:10.1111/j. 1365-2486.2006.01288.x

Dubuis A, Giovanettina S, Pellissier L, Pottier J, Vittoz P, Guisan A (2012) Improving the prediction of plant species distribution and community composition by adding edaphic to topo-climatic variables. J Veg Sci 24:593-606. doi:10.1111/jvs.12002

Duru M, Cruz P, Magda D (2004) Using plant traits to compare sward structure and composition of grass species across environmental gradients. Appl Veg Sci 7:11-18. doi:10.1111/j.1654-109x.2004. tb00590.x

Duru M, Adam M, Cruz P, Martin G, Ansquer P, Ducourtieux C, Jouany C, Theau JP, Viegas J (2009) Modelling above-ground herbage mass for a wide range of grassland community types. Ecol Model 220: 209-225. doi:10.1016/j.ecolmodel.2008.09.015

Elton CS (1927) Animal ecology. Sidgwick \& Jackson, London

Emerson BC, Gillespie RG (2008) Phylogenetic analysis of community assembly and structure over space and time. Trends Ecol Evol 23: 619-630. doi:10.1016/j.tree.2008.07.005

Falster DS, Moles AT, Westoby M (2008) A general model for the scaling of offspring size and adult size. Am Nat 172(3):299-317. doi:10. $1086 / 589889$

Falster DS, Brännström A, Dieckmann U, Westoby M (2011) Influence of four major plant traits on average height, leaf-area cover, net primary productivity, and biomass density in single-species forests: a theoretical investigation. J Ecol 99:148-164. doi:10.1111/j.13652745.2010.01735.x

Finn JA, Kirwan L, Connolly J, Sebastia MT, Helgadottir A, Baadshaug $\mathrm{OH}$, Belanger G, Black A, Brophy C, Collins RP, Cop J, Dalmannsdottir S, Delgado I, Elgersma A, Fothergill M, FrankowLindberg BE, Ghesquiere A, Golinska B, Golinski P, Grieu P, Gustavsson AM, Hoglind M, Huguenin-Elie O, Jørgensen M, Kadziuliene Z, Kurki P, Llurba R, Lunnan T, Porqueddu C, Suter M, Thumm U, Lüscher A (2013) Ecosystem function enhanced by combining four functional types of plant species in intensively managed grassland mixtures: a 3-year continental-scale field experiment. J Appl Ecol 50:365-375. doi:10.1111/1365-2664.12041 
Fort F, Jouany C, Cruz P (2013) Root and leaf functional trait relations in Poaceae species: implications of differing resource acquisition strategies. J Plant Ecol 6:211-219. doi:10.1093/jpe/rts034

Fort F, Cruz P, Jouany C (2014) Hierarchy of root functional trait values and plasticity drive early-stage competition for water and phosphorus among grasses. Funct Ecol 28:1030-1040. doi:10.1111/13652435.12217

Franklin KA (2008) Shade avoidance. New Phytol 179:930-944. doi:10. $1111 / j .1469-8137.2008 .02507 . x$

Franklin O, Agren GI (2002) Leaf senescence and resorption as mechanisms of maximizing photosynthetic production during canopy development at $\mathrm{N}$ limitation. Funct Ecol 16:727-733. doi:10.1046/j. 1365-2435.2002.00674.x

Freschet GT, Dias ATC, Ackerly DD, Aerts R, van Bodegom PM, Cornwell WK et al (2011) Global to community scale differences in the prevalence of convergent over divergent leaf trait distributions in plant assemblages. Glob Ecol Biogeogr 20:755-765. doi:10.1111/ j.1466-8238.2011.00651.x

Garnier E, Navas ML (2012) A trait-based approach to comparative functional plant ecology: concepts, methods and applications for agroecology. A review. Agron Sustain Dev 32:365-399. doi:10.1007/ s13593-011-0036-y

Gastal F, Nelson CJ (1994) Nitrogen use within the growing leaf blade of tall fescue. Plant Physiol 105:191-197. doi:10.1104/pp.105.1.191

Gerhold P, Price JN, Pussa K, Kalamees R, Aher K, Kaasik A et al (2013) Functional and phylogenetic community assembly linked to changes in species diversity in a long-term resource manipulation experiment. J Veg Sci 24:843-852. doi:10.1111/jvs.12052

Gibson DJ (2009) Grasses and grassland ecology. Oxford University Press Inc., New York, p 305

Givnish T (1978) Ecological aspect of plant morphology: leaf form in relation to environment. In: Theoretical plant morphology. Sattler, R. Edition

Givnish TJ (1988) Adaptation to sun and shade: a whole-plant perspective. Aust J Plant Physiol 15:63-92. doi:10.1071/PP9880063

Gommers CMM, Visser EJW, Onge KRS, Voesenek LACJ, Ronald P (2013) Shade tolerance: when growing tall is not an option. Trends Plant Sci 18(2):1360-1385. doi:10.1016/j.tplants.2012.09.008

Grassein F, Till-Bottraud I, Lavorel S (2010) Plant resource-use strategies: the importance of phenotypic plasticity in response to a productivity gradient for two subalpine species. Ann Bot 106:637-645. doi:10.1093/aob/mcq154

Gravel D, Canham CD, Beaudet M, Messier C (2006) Reconciling niche and neutrality: the continuum hypothesis. Ecol Lett 9:399-409. doi: 10.1111/j.1461-0248.2006.00884.x

Grigulis K, Lavorel S, Krainer U, Legay N, Baxendale C, Dumont M, Kastl E, Arnoldi C, Bardgett RD, Poly F, Pommier T, Schloter M, Tappeiner U, Bahn M, Clément JC (2013) Relative contributions of plant traits and soil microbial properties to mountain grassland ecosystem services. J Ecol 101:47-57. doi:10.1111/1365-2745.12014

Grime JP (1977) Evidence for existence of 3 primary strategies in plants and its relevance to ecological and evolutionary theory. Am Nat 111: 1169-1194. doi:10.1086/283244

Grime JP (1993) Vegetation functional classification systems as approaches to predicting and quantifying global vegetation change. In: Solomon A, Shugart H (eds) Vegetation dynamics global change. Chapman and Hall, New York, pp 293-305

Grime JP (1998) Benefits of plant diversity to ecosystems: immediate, filter and founder effects. J Ecol 86:902-910. doi:10.1046/j.13652745.1998.00306.x

Grime JP (2001) Plant strategies, vegetation processes and ecosystem properties, 2nd edn. Wiley, Chichester

Grime JP (2006) Trait convergence and trait divergence in herbaceous plant communities: mechanisms and consequences. J Veg Sci 17: 255-260. doi:10.1111/j.1654-1103.2006.tb02444.x
Grime JP, Pierce S (2012) The evolutionary strategies that shape ecosystems. Wiley-Blackwell, Chichester

Grime JP, Hodgson JG, Hunt R (1988) Comparative plant ecology: a functional approach to common British species. Unwin Hyman, London

Grime JP, Thompson K, Hunt R, Hodgson JG, Cornelissen JHC, Rorison IH, Hendry GAF, Ashenden TW, Askew AP, Band SR et al (1997) Integrated screening validates primary axes of specialisation in plants. Oikos 79:259-281. doi:10.2307/3546011

Grinnell J (1917) The niche relationship of the California Thrasher. Auk 34:427-433. doi:10.1098/rsbl.2009.1024

Gross N, Suding KN, Lavorel S (2007a) Leaf dry matter content and lateral spread predict response to land use change for six subalpine grassland species. J Veg Sci 18:289-300. doi:10.1111/j.1654-1103. 2007.tb02540.x

Gross N, Suding KN, Lavorel S, Roumet C (2007b) Complementarity as a mechanism of coexistence between functional groups of grasses. $\mathrm{J}$ Ecol 95:1296-1305. doi:10.1111/j.1365-2745.2007.01303.x

Gross N, Kunstler G, Liancourt P, de Bello F, Suding KN, Lavorel S (2009) Linking individual response to biotic interactions with community structure: a trait-based framework. Funct Ecol 23:11671178. doi:10.1111/j.1365-2435.2009.01591.x

Gross N, Börger L, Soriano-Morales SI, Le Bagousse-Pinguet Y, Quero JL, García-Gómez M, Valencia-Gómez E, Maestre FT (2013a) Uncovering multiscale effects of aridity and biotic interactions on the functional structure of Mediterranean shrublands. J Ecol 101: 637-649. doi:10.1111/1365-2745.12063

Gross N, Börger L, Duncan RP, Hulme PE (2013b) Functional differences between alien and native species: do biotic interactions determine the functional structure of highly invaded grasslands? Funct Ecol 27:1262-1272. doi:10.1111/1365-2435.12120

Gutschick VP (1999) Biotic and abiotic consequences of differences in leaf structure. New Phytol 143:3-18. doi:10.1046/j.1469-8137. 1999.00423.x

Harpole WS, Tilman D (2007) Grassland species loss resulting from reduced niche dimension. Nature 446:791-793. doi:10.1038/ nature 05684

Hejcman M, Hejcmanova P, Pavlu V, Benes J (2013) Origin and history of grasslands in Central Europe - a review. Grass Forage Sci 68: 345-363. doi:10.1111/gfs. 12066

Herrero M, Grace D, Njuki J, Johnson N, Rufino M (2013) The roles of livestock in developing countries. Animal 7(s1):3-18. doi:10.1017/ S1751731112001954

HilleRisLambers J, Adler PB, Harpole WS, Levine JM, Mayfield MM (2012) Rethinking community assembly through the lens of coexistence theory. Annu Rev Ecol Evol Syst 43:227-248. doi:10.1146/ annurev-ecolsys-110411-160411

Hirose T, Bazzaz FA (1998) Trade-off between light- and nitrogen-use efficiency in canopy photosynthesis. Ann Bot 82:195-202. doi:10. 1006/anbo.1998.0668

Hoekstra NJ, Suter M, Finn JA, Husse S, Lüscher A (2015) Do belowground vertical niche differences between deep and shallow-rooted species enhance resource uptake and drought resistance in grassland mixtures? Plant Soil. doi:10.1007/s11104-014-2352-x

Holdaway RJ, Sparrow AD (2006) Assembly rules operating along a primary riverbed-grassland successional sequence. J Ecol 94: 1092-1102. doi:10.1111/j.1365-2745.2006.01170.x

Hubbell SP (2001) The unified neutral theory of biodiversity and biogeography. Princeton University Press, Princeton

Hutchinson GE (1957) Concluding remarks. Pages 415-427 in Cold Spring Harbor symposia on quantitative biology

Jenny H (1941) Factors of soil formation: a system of quantitative pedology. Dover, New York, p 320

Jung V, Violle C, Mondy C, Hoffmann L, Muller S (2010) Intraspecific variability and trait-based community assembly. J Ecol 98:1134 1140. doi:10.1111/j.1365-2745.2010.01687.x 
Ke P-J, Miki T, Ding T-S (2015) The soil microbial community predicts the importance of plant traits in plant-soil feedback. New Phytol 206:329-341. doi:10.1111/nph.13215

Keddy PA (1992) Assembly and response rules - 2 goals for predictive community ecology. J Veg Sci 3:157-164. doi:10.2307/3235676

Kikuzawa K, Onoda Y, Wright IJ, Reich PR (2013) Mechanisms underlying global temperature-related patterns in leaf longevity. Glob Ecol Biogeogr 22:982-993. doi:10.1111/geb.12042

Kitajima K (1994) Relative importance of photosynthetic traits and allocation patterns as correlates of seedling shade tolerance of 13 tropical trees. Oecologia 98:419-428. doi:10.1007/BF00324232

Kraft NJB, Ackerly DD (2010) Functional trait and phylogenetic tests of community assembly across spatial scales in an Amazonian forest. Ecol Monogr 80:401-422. doi:10.1890/09-1672.1

Kraft NJB, Valencia R, Ackerly DD (2008) Functional traits and nichebased tree community assembly in an Amazonian forest. Science 322:580-582. doi:10.1126/science. 1160662

Kunstler G, Lavergne S, Courbaud B, Thuiller W, Vieilledent G, Zimmermann NE et al (2012) Competitive interactions between forest trees are driven by species' trait hierarchy, not phylogenetic or functional similarity: implications for forest community assembly. Ecol Lett 15:831-840. doi:10.1111/j.1461-0248.2012.01803.x

Kyriazopoulos AP, Abraham EM, Parissi ZM, Koukoura Z, Nastis AS (2012) Forage production and nutritive value of Dactylis glomerata and Trifolium subterraneum mixtures under different shading treatments. Grass Forage Sci 68:72-82. doi:10.1111/j.1365-2494.2012. 00870.x

Laliberté E et al (2012) Which plant traits determine abundance under long-term shifts in soil resource availability and grazing intensity? J Ecol 100:662-677. doi:10.1111/j.1365-2745.2011.01947.x

Laliberté E, Norton D, Scott D (2013) Contrasting effects of productivity and disturbance on plant functional diversity at local and metacommunity scales. J Veg Sci 24:834-842. doi:10.1111/jvs. 12044

Laliberté E, Zemunik G, Turner BL (2014) Environmental filtering explains variation in plant diversity along resource gradients. Science 345:1602-1605. doi:10.1126/science. 1256330

Laughlin DC (2014) Applying trait-based models to achieve functional targets for theory-driven ecological restoration. Ecol Lett 17:771784. doi:10.1111/ele. 12288

Laughlin DC, Laughlin DE (2013) Advances in modelling trait-based plant community assembly. Trends Plant Sci 18:584-593. doi:10. 1016/j.tplants.2013.04.012

Laughlin DC, Joshi C, van Bodegom PM, Bastow ZA, Fulé PZ (2012) A predictive model of community assembly that incorporates intraspecific trait variation. Ecol Lett 15:1291-1299. doi:10.1111/j.14610248.2012.01852.x

Laughlin DC, Joshi C, Richardson SJ, Peltzer DA, Mason NWH, Wardle DA (2015) Quantifying multimodal trait distributions improves trait-based predictions of species abundances and functional diversity. J Veg Sci 26:46-57. doi:10.1111/jvs.12219

Lavorel S, Garnier E (2002) Predicting changes in community composition and ecosystem functioning from plant traits: revisiting the Holy Grail. Funct Ecol 16:545-556. doi:10.1046/j.1365-2435.2002. 00664.x

Lavorel S, Díaz S, Hans J, Cornelissen JHC, Garnier E, Harrison SP, McIntyre S, Pausas JG, Perez-Harguindeguy N, Roumet C, Urcelay C (2007) Plant functional types: are we getting any closer to the Holy Grail? In J. Canadell, L. F. Pitelka, and D. Pataki, eds. Terrestrial ecosystems in a changing world. IGBP book series. Springer-Verlag, Berlin. $336 \mathrm{p}$

Lavorel S, Grigulis K, Lamarque P, Colace M-P, Garden D, Girel J, Pellet G, Douzet R (2011) Using plant functional traits to understand the landscape distribution of multiple ecosystem services. J Ecol 99: 135-147. doi:10.1111/j.1365-2745.2010.01753.x
Lazzarotto P, Calanca P, Fuhrer J (2009) Dynamics of grass-clover mixtures - an analysis of the response to management with the PROductive GRASsland Simulator (PROGRASS). Ecol Model 220:703-724. doi:10.1016/j.ecolmodel.2008.11.023

Legay N, Baxendale C, Grigulis K, Krainer U, Kastl E, Schloter M, Bardgett RD, Arnoldi C, Bahn M, Dumont M, Poly F, Pommier T, Clement JC, Lavorel S (2014) Contribution of above- and belowground plant traits to the structure and function of grassland soil microbial communities. Ann Bot 114:1011-1021. doi:10.1093/ aob/mcu169

Leuschner C, Gebel S, Rose L (2013) Root trait responses of six temperate grassland species to intensive mowing and NPK fertilisation: a field study in a temperate grassland. Plant Soil 373:687-698. doi:10. 1007/s11104-013-1836-4

Levine JM, HilleRisLambers J (2009) The importance of niches for the maintenance of species diversity. Nature 461:254-257. doi:10.1038/ nature 08251

Loreau M, Hector A (2001) Partitioning selection and complementarity in biodiversity experiments. Nature 412:72-76. doi:10.1038/ 35083573

Lortie CJ, Brooker RW, Choler P, Kikvidze Z, Michalet R, Pugnaire FI, Callaway RM (2004) Rethinking plant community theory. Oikos 107:433-438. doi:10.1111/j.0030-1299.2004.13250.x

Louault F, Pillar VD, Aufrère J, Garnier E, Soussana JF (2005) Plant traits and functional types in response to reduced disturbance in a seminatural grassland. J Veg Sci 16:151-160. doi:10.1111/j.1654-1103. 2005.tb02350.x

MacArthur R (1964) Competition, habitat selection and character displacement in a patchy environment. PNAS 61:1207-1210. doi:10. 1073/pnas.90.10.4329

MacArthur R, Levins R (1967) The limiting similarity, convergence and divergence of coexisting species. Am Nat 101:377-385. doi:10. $1086 / 282505$

Maire V, Gross N, da Pontes LS, Picon-Cochard C, Soussana JF (2009) Trade-off between root nitrogen acquisition and shoot nitrogen utilization across 13 co-occurring pasture grass species. Funct Ecol 23: 668-679. doi:10.1111/j.1365-2435.2009.01557.x

Maire V, Gross N, da Pontes LS, Proulx R, Wirth C et al (2012a) Habitatfiltering and niche differentiation jointly determine species abundance along fertility and disturbance gradients. New Phytol 196(2):497-509. doi:10.1111/j.1469-8137.2012.04287.x

Maire V, Martre P, Kattge J, Gastal F, Esser G, Fontaine S, Soussana J-F (2012b) The coordination of leaf photosynthesis links $\mathrm{C}$ and $\mathrm{N}$ fluxes in $\mathrm{C}_{3}$ plant species. PLoS One 7(6):e38345. doi:10.1371/ journal.pone. 0038345

Maire V, Gross N, Hill D, Martin R, Wirth C, Wright IJ, Soussana J-F (2013a) Disentangling coordination among functional traits using an individual-centred model: impact on plant performance at intra- and inter-specific levels. PLoS One 8(10):e77372. doi:10.1371/journal. pone. 0077372

Maire V, Soussana JF, Gross N, Bachelet B, Martin R et al (2013b) Plasticity of plant form and function sustains productivity and dominance along environment and competition gradients. A modeling experiment with Gemini. Ecol Model 254:80-91. doi:10.1016/j. ecolmodel.2012.03.039

Maire V, Wright IJ, Prentice IC, Batjes NH, Bhaskar R, van Bodegom PM, Cornwell WK, Ellsworth D, Niinemets Ü, Ordoñez A, Reich PB, Santiago LS (2015) Global soil and climate effects on leaf photosynthetic traits and rates. Global Ecol Biogeogr (accepted)

Marks CO, Lechowicz MJ (2006) A holistic tree seedling model for the investigation of functional trait diversity. Ecol Model 193:141-181. doi:10.1016/j.ecolmodel.2005.09.011

Martineau Y, Saugier B (2007) A process-based model of old field succession linking ecosystem and community ecology. Ecol Model 204(34):399-419. doi:10.1016/j 
Mason NWH, de Bello F, Doležal J, Lepš J (2011) Niche overlap reveals the effects of competition, disturbance and contrasting assembly processes in experimental grassland communities. J Ecol 99:788796. doi:10.1111/j.1365-2745.2011.01801.x

Mayfield MM, Levine JM (2010) Opposing effects of competitive exclusion on the phylogenetic structure of communities. Ecol Lett 13: 1085-1093. doi:10.1111/j.1461-0248.2010.01509.x

McGill BJ, Enquist BJ, Weiher E, Westoby M (2006) Rebuilding community ecology from functional traits. Trends Ecol Evol 21:178 185. doi:10.1016/j.tree.2006.02.002

McIntyre S, Lavorel S, Landsberg J, Forbes TDA (1999) Disturbance response in vegetation towards a global perspective on functional traits. J Veg Sci 10(5):621-630. doi:10.2307/3237077

McMurtrie RE, Iversen CM, Dewar RC, Medlyn BE, Näsholm T, Pepper DA, Norby RJ (2012) Plant root distributions and nitrogen uptake predicted by a hypothesis of optimal root foraging. Ecol Evol 2(6): 1235-1250. doi:10.1002/ece3.266

McNickle GG, Dybzinski R (2013) Game theory and plant ecology. Ecol Lett 16:545-555. doi:10.1111/ele.12071

Medlyn BE, Duursma RA, Eamus D, Ellsworth DS, Prentice IC, Barton CVM, Crous KY, De Angelis P, Freeman M, Wingate L (2011) Reconciling the optimal and empirical approaches to modelling stomatal conductance: reconciling optimal and empirical stomatal models. Glob Chang Biol 17:2134-2144. doi:10.1111/j.13652486.2010.02375.x

Merow C, Latimer AM, Silander JA Jr (2011) Can entropy maximization use functional traits to explain species abundances? A comprehensive evaluation. Ecology 92:1523-1537. doi:10.1890/10-1174.1

Millenium Assessment (2005) http://www.millennium assessment.org. Assessed 16 Oct 2014

Murrell DJ (2010) When does local spatial structure hinder competitive coexistence and reverse competitive hierarchies? Ecology 91:16051616. doi:10.1890/09-0832.1

Niemann GJ, Pureveen JBM, Eijkel GG, Poorter H, Boon JJ (1992) Differences in relative growth rate in 11 grasses correlate with differences in chemical composition as determined by pyrolysis mass spectrometry. Oecologia 89(4):567-573. doi:10.1007/BF00317165

Niinemets U (2010) A review of light interception in plant stands from leaf to canopy in different plant functional types and in species with varying shade tolerance. Ecol Res 25:693-714. doi:10.1007/ s11284-010-0712-4

Niinemets U (2015) Is there a species spectrum within the world-wide leaf economics spectrum? Major variations in leaf functional traits in the Mediterranean sclerophyll Quercus ilex. New Phytol 205:79-96. doi:10.1111/nph.13001

Ojima DS, Parton WJ, Schimel DS, Scurlock JMO, Kittel TGF (1993) Modelling the effects of climatic and $\mathrm{CO}_{2}$ changes on grassland storage of soil C. Water Air Soil Pollut 70:643-657. doi:10.1007/ 978-94-011-1982-5 43

Pacala SW, Tilman D (1994) Limiting similarity in mechanistic and spatial models of plant competition in heterogeneous environments. Am Nat 143:222-257. doi:10.1086/285602

Pakeman RJ (2004) Consistency of plant species and trait responses to grazing along a productivity gradient: a multi-site analysis. J Ecol 92:893-905

Perez-Harguindeguy N, Díaz S, Vendramini F, Cornelissen JHC, Gurvich DE, Cabido M (2003) Leaf traits and herbivore selection in the field and in cafeteria experiments. Austral Ecol 28:642-650. doi:10.1046/ j.1442-9993.2003.01321.x

Peri PL, Lucas RJ, Moot DJ (2007) Dry matter production, morphology and nutritive value of Dactylis glomerata growing under different light regimes. Agrofor Syst 70:63-79. doi:10.1007/s10457-0079029-x

Polley HW, Isbell FI, Wilsey BJ (2013) Plant functional traits improve diversity-based predictions of temporal stability of grassland productivity. Oikos 122:1275-1282. doi:10.1111/j.1600-0706. 2013.00338.x

Poorter H, Van Der Werf A, Atkin OK, Lambers H (1991) Respiratory energy requirements of roots vary with the potential growth rate of a plant species. Physiol Plant 83:469-475. doi:10.1111/j.1399-3054. 1991.tb00122.x

Prentice IC, Dong N, Gleason SM, Maire V, Wright IJ (2014) Balancing the costs of carbon gain and water transport: testing a new theoretical framework for plant functional ecology. Ecol Lett 17:82-91. doi:10. 1111/ele. 12211

Price JN, Gazol A, Tamme R, Hiiesalu I, Pärtel M (2014) The functional assembly of experimental grasslands in relation to fertility and resource heterogeneity. Funct Ecol 28:509-519. doi:10.1111/13652435.12186

Reich PB (2014) The world-wide 'fast-slow' plant economics spectrum: a traits manifesto. J Ecol 102:275-301. doi:10.1111/1365-2745. 12211

Reynolds SG, Batello C, Baas S, Mack S (2005) Grasslands and forage to improve livelihoods and reduce poverty. In (ed. D.A. Gilloway): "Grassland: a global resource", Proceedings of the XXth International Grassland Congress, Dublin, Ireland, Wageningen Academic Publishers, Wageningen, The Netherlands, p. 323-338

Ryser P, Urbas P (2000) Ecological significance of leaf life span among Central European grass species. Oikos 91:41-50. doi:10.1034/j. 1600-0706.2000.910104.x

Schellberg J, da Pontes LS (2012) Plant functional traits and nutrient gradients on grassland. Grass Forage Sci 67:305-319. doi:10.1111/ j.1365-2494.2012.00867.x

Seidlova L, Verlinden M, Gloser J, Milbau A, Nijs I (2009) Which plant traits promote growth in the low-light regimes of vegetation gaps? Plant Ecol 200:303-318. doi:10.1007/s11258-008-9454-6

Shipley B (2009) From plant traits to vegetation structure. Chance and selection in the assembly of ecological communities. Cambridge University Press, Cambridge

Shipley B, Almeida-Cortez J (2003) Interspecific consistency and intraspecific variability of specific leaf area with respect to irradiance and nutrient availability. Ecoscience 10(1):74-79

Shipley B, Vile D, Garnier E (2006) From plant traits to plant communities: a statistical mechanistic approach to biodiversity. Science 314: 812-814. doi:10.1126/science.1131344

Smith H, Whitelam GC (1997) The shade avoidance syndrome: multiple responses mediated by multiple phytochromes. Plant Cell Environ 20:840-844. doi:10.1046/j.1365-3040.1997.d01-104.x

Smith P, Martino D, Cai Z, Gwary D, Janzen H, Kumar P, McCarl B, Ogle S, O'Mara F, Rice C, Scholes B, Sirotenko O, Howden M, McAllister T, Pan G, Romanenkov V, Schneider U, Towprayoon S, Wattenbach M, Smith J (2008) Greenhouse gas mitigation in agriculture. Philos Trans R Soc Lond Ser B Biol Sci 363:789-813. doi: 10.1098/rstb.2007.2184

Sonnier G et al (2010) Plant traits, species pools and the prediction of relative abundance in plant communities: a maximum entropy approach. J Veg Sci 21:318-331. doi:10.1111/j.1654-1103.2009. 01145.x

Soussana JF, Teyssonneyre F, Picon-Cochard C, Dawson L (2005) A trade-off between nitrogen uptake and use increases responsiveness to elevated $\mathrm{CO}_{2}$ in infrequently cut mixed $\mathrm{C}_{3}$ grasses. New Phytol 166:217-230. doi:10.1111/j.1469-8137.2005.01332.x

Soussana JF, Maire V, Gross N, Hill D, Bachelet B, Martin R, Pages L, Wirth C (2012) Gemini: a grassland model simulating the role of plant traits for community dynamics and ecosystem functioning: part I: parameterization and evaluation. Ecol Model 231:134-145. doi:10.1016/j.ecolmodel.2012.02.002

Soussana JF, Barioni LG, Ari TB, Conant R, Gerber P, Havlik P, Ickowicz A, Howden M (2013) Managing grassland systems in a changing climate: the search for practical solutions. In: Revitalizing grasslands 
to sustain our communities. Michalk, D.L., et al., (eds.). Proceedings of the 22nd International Grassland Congress, Sidney, 15-19 September, 2013, p. 10-27

Spasojevic MJ, Suding KN (2012) Inferring community assembly mechanisms from functional diversity patterns: the importance of multiple assembly processes. J Ecol 100:652-661. doi:10.1111/j.1365-2745. 2011.01945.x

Suding KN, Goldberg DE, Hartman KM (2003) Relationships among species traits: separating levels of response and identifying linkages to abundance. Ecology 84:1-16. doi:10.1890/0012-9658(2003) 084[0001:RASTSL]2.0.CO;2

Suding KN, Lavorel S, Chapin FS, Cornelissen JHC, Díaz S, Garnier E, Goldberg D, Hooper D, Jackson ST, Navas ML (2008) Scaling environmental change through the community-level: a trait-based response-and-effect framework for plants. Glob Chang Biol 14: 1125-1140. doi:10.1111/j.1365-2486.2008.01557.x

Sugiyama S (2005) Developmental basis of interspecific differences in leaf size and specific leaf area among $\mathrm{C}_{3}$ grass species. Funct Ecol 19:916-924. doi:10.1111/j.1365-2435.2005.01044.x

Tomlinson KW, Dominy JG, Hearne JW, O'Connor TG (2007) A functional-structural model for growth of clonal bunchgrasses. Ecol Model 202:243-264. doi:10.1016/j.ecolmodel.2006.11.002

Valladares F, Niinemets U (2008) Shade tolerance, a key plant feature of complex nature and consequences. Annu Rev Ecol Evol Syst 39: 237-257. doi:10.1146/annurev.ecolsys.39.110707.173506

Valladares F, Sanchez-Gomez D, Zavala MA (2006) Quantitative estimation of phenotypic plasticity: bridging the gap between the evolutionary concept and its ecological applications. J Ecol 94:11031116. doi:10.1111/j.1365-2745.2006.01176.x

Valladares F, Saldaña A, Gianoli E (2012) Costs versus risks: architectural changes with changing light quantity and quality in saplings of temperate rainforest trees of different shade tolerance. Austral Ecol 37: 35-43. doi:10.1111/j.1442-9993.2011.02245.x 3

Van Arendonk JJCM, Poorter H (1994) The chemical composition and anatomical structure of leaves of grass species differing in relative growth rate. Plant Cell Environ 17:963-970. doi:10.1111/j.13653040.1994.tb00325.x

Violle C, Jiang L (2009) Towards trait-based quantification of species niche. J Plant Ecol 2:87-93. doi:10.1093/jpe/rtp007
Violle C, Navas M-L, Vile D, Kazakou E, Fortunel C, Hummel I, Garnier E (2007) Let the concept of trait be functional! Oikos 116:882-892. doi:10.1111/j.2007.0030-1299.15559.x

Weiher E, Keddy P (1995) Assembly rules, null models, and trait dispersion: new questions from old patterns. Oikos 74:159-164. doi:10. $2307 / 3545686$

Weiher E, Clarke GDP, Keddy PA (1998) Community assembly rules, morphological dispersion, and the coexistence of plant species. Oikos 81:309-322. doi:10.2307/3547051

Westoby M (1998) A leaf-height-seed (LHS) plant ecology strategy scheme. Plant Soil 199:213-227. doi:10.1023/A:1004327224729

Westoby M (1999) A LHS strategy scheme in relation to grazing and fire. In: Eldridge D, Freudenberger D (eds) Proceedings of the VIth International Rangeland Congress. Australian Rangeland Society, Queensland, pp 893-896

Westoby M, Wright IJ (2006) Land-plant ecology on the basis of functional traits. Trends Ecol Evol 21:261-268. doi:10.1016/j.tree.2006. 02.004

Westoby M, Falster DS, Moles AT, Vesk PA, Wright IJ (2002) Plant ecological strategies: some leading dimensions of variation between species. Annu Rev Ecol Syst 33:125-159. doi:10.1146/annurev. ecolsys.33.010802.150452

Whittaker RH (1975) Communities and ecosystems, 2nd edn. Macmillan, New York

Woodward SL (2008) Grassland biomes, guides to biomes of the world. Greewood Press (Eds), Westport, Connecticut; pp 148

Wright IJ, Westoby M (2000) Cross-species relationships between seedling relative growth rate, nitrogen productivity and root vs. leaf function in 28 Australian woody species. Funct Ecol 14:97-107. doi:10.1046/j.1365-2435.2000.00393.x

Wright IJ, Reich PB, Westoby M et al (2004) The worldwide leaf economic spectrum. Nature 428:821-827. doi:10.1038/nature02403

Zuppinger-Dingley D, Schmid B, Petermann JS, Yadav V, De Deyn GB, Flynn DFB (2014) Selection for niche differentiation in plant communities increases biodiversity effects. Nature 515:108-111. doi:10. 1038/nature13869

Zwicke M, Picon-Cochard C, Morvan-Bertrand A, Prud'homme MP, Volaire F (2015) What functional strategies drive drought survival and recovery of perennial species from upland grassland? Ann Bot, accepted, in press 